\title{
On the Instability Threshold of Journal Bearing Supported Rotors
}

\author{
Ricardo Ugliara Mendes and Katia Lucchesi Cavalca \\ Laboratory of Rotating Machinery, Department of Mechanical Design, Faculty of Mechanical Engineering, University of Campinas, \\ 200 Mendeleiev Street, 13083-970 Campinas, SP, Brazil
}

Correspondence should be addressed to Katia Lucchesi Cavalca; katia@fem.unicamp.br

Received 18 July 2013; Accepted 31 October 2013; Published 3 February 2014

Academic Editor: Hooshang Heshmat

Copyright (C) 2014 R. U. Mendes and K. L. Cavalca. This is an open access article distributed under the Creative Commons Attribution License, which permits unrestricted use, distribution, and reproduction in any medium, provided the original work is properly cited.

\begin{abstract}
Journal bearing supported rotors present two kinds of self-excited vibrations: oil-whirl and oil-whip. The first one is commonly masked by the rotor unbalance, hence being rarely associated with instability problems. Oil-whip is a severe vibration which occurs when the oil-whirl frequency coincides with the first flexural natural frequency of the shaft. In many cases, oil-whip is the only fluid-induced instability considered during the design stage; however, experimental evidences have shown that the instability threshold may occur much sooner, demanding a better comprehension of the instability mechanism. In this context, numerical simulations were made in order to improve the identification of the instability threshold for two test rig configurations: one on which the instability occurs on the oil-whip frequency, and another which became unstable before this threshold. Therefore, the main contribution of this paper is to present an investigation of two different thresholds of fluid-induced instabilities and their detectability on design stage simulations based on rotordynamic analysis using linear speed dependent coefficients for the bearings.
\end{abstract}

\section{Introduction}

Rotating machinery supported by journal bearings present two kinds of self-excited vibrations, namely, oil-whirl and oilwhip, which can drive the system to an unstable condition.

The understanding of the stability threshold phenomena and how they influence the dynamic response of the system has been a topic of great concern since the first studies of the lubrication theory, dating from the 1880s with the works of Petrov [1-4], Tower [5, 6], and Reynolds [7].

Oil-whirl is a subsynchronous vibration, occurring near half the rotational speed of the shaft: $43 \%$ to $49 \%$ according to Oliver [8]. It is usually masked by rotor unbalance and it can usually be seen only in the bearings. Oil-whip is a severe vibration that occurs once the oil-whirl coincides with the first flexural natural frequency of the shaft, hence, near twice this natural frequency. When operating under this condition, the vibration amplitudes in the bearings are limited by the bearings clearance; however, the shaft vibration can be very high once the shaft vibrates in a resonant condition-its natural frequency. The oil-whip instability was first described in the works of Newkirk $[9,10]$, and a more extensive description of these self-excited vibrations was made in the surveys of Muszynska [11, 12], who also evaluated stability regions using simple models. According to Muszynska [11], often the term "unstable," when talking about oil-whirl and oil-whip, is rather close to the terms "undesired" or "unacceptable," once that both phenomena present a periodic pattern, which, however, inserts a subharmonic component as significant as the harmonic component due to unbalance, in this case, designated by instability. In its purest sense "instability" refers to vibrations growing without bound. In this case, a limit cycle subsynchronous vibration may have large orbits, limited by the bearing damping. However, in order to maintain the term usually used in the literature, the instability threshold refers here to the point when the oil-whirl phenomenon begins.

Therefore, the contribution of this work is the stability analysis process itself, that is, how the conventional rotordynamic analysis can lead to the understanding of the instability threshold in different rotor-bearings systems and how the information of the fluid frequencies can help in this matter, 
once these frequencies are not usually taken into account in the classical analysis.

Aiming at a better estimation of a rotor critical speed, Stodola [13] and Hummel [14] considered the flexibility of the bearing oil film, introducing the idea of representing its dynamic properties by means of springs and dampers. This idea was explored in a more formal way in the work of Lund [15], where equivalent linear coefficients of stiffness and damping were calculated through the simplified solution of the Reynolds equation. Recently, a finite-difference method was used to solve the Reynolds equation in the work of Machado and Cavalca [16], and a finite-volume method was used in Machado [17], both intending to calculate more accurate equivalent coefficients, based on the previous work of Lund.

During the development of the equivalent linear coefficients, other researches were made towards nonlinear methods; for example, Capone [18, 19] presented a nonlinear solution for the Reynolds equation, obtaining a nonlinear equation for the force exerted by the journal bearings on the shaft.

In this context, many authors [20-22] used finite element models (FEM) of shafts together with journal bearings models to increase the understanding of complex rotors. Lima [23] made simulations with Capone's model and extended it to tilting-pad bearings. Castro et al. [24] used the same bearing model with a FEM model based in the work of Nelson and McVaugh [25] to study the stability threshold of horizontal and vertical machines, achieving good agreement with experimental results.

In the existing literature, oil-whirl is commonly referred to as a weak self-excited vibration, nevertheless, treated as instability. The first part of this statement relies on the fact that oil-whirl effect is not observable in the rotor, once its vibration is dominated by the unbalance forces. The vibration amplitude of the shaft inside the bearings is a strong function of the eccentricity of the shaft within the bearing clearance, that is, the bearing eccentricity. An important concept regarding this matter is the eccentricity ratio, which is a dimensionless quantity given by the bearing eccentricity divided by the bearing radial clearance. Concerning vertical rotors or lightly loaded horizontal rotors (with very low eccentricity ratio) the oil-whirl vibration in the bearing is limited by the fluid forces and the bearing clearance; this occurs because, as discussed later, in these rotors the crosscoupled coefficients of stiffness increase drastically as the rotor accelerates, overcoming the dissipative forces of the damping coefficients.

In some cases, this vibration due to oil-whirl may cause heating and wear in the bearing, justifying the use of the term instability. In such light rotors, it is also possible that the oil-whirl component becomes very small or vanishes during the rotor crossover through the critical speed, giving place to the rise of the synchronous component due to unbalance [11]. For horizontal rotors with higher eccentricity ratio, the subsynchronous oil-whirl component may be present in the bearings but usually with small amplitudes.
Therefore, when talking about stability threshold on horizontal rotors, oil-whip is the phenomenon usually considered. However, experimental evidences have shown that, in some cases, the instability threshold may occur sooner than the expected oil-whip frequency. Such observations were made in a test rig at the Laboratory of Rotating Machinery in the University of Campinas, when simulating a procedure for stability identification of journal bearing supported machines.

Thereby, the correct identification of the instability threshold is mandatory to ensure the expected performance in a secure operating condition, still during the design stage, remarkably in the case of high speed flexible rotors (e.g., multistage rotors present in power plants). The previous knowledge of the instability threshold may be also useful to the development of control systems to stabilize the fluidinduced instabilities, allowing the rotors to safely operate in higher rotational speeds. Siqueira et al. [26] developed a linear parameter varying (LPV) control, which takes into account the parameter dependency of the system (in this case, the rotational speed), using the $\mathrm{H}$-infinite technique. A significant vibration amplitude reduction during the crossing of the critical speed in a run-up simulation was obtained using a magnetic actuator. The authors stated that an important factor in the control design was a representative model; which they obtained using the linear coefficients approach. Riemann et al. [27] took a step further and managed to control the oil-whip instability using a $\mu$-synthesis control, extending the rotor operational range from $42 \mathrm{~Hz}$ (oil-whip threshold) up to $60 \mathrm{~Hz}$ in an experimental test rig; a magnetic actuator was used as well. Tuma et al. [28] extended the instability threshold of a rigid rotor from $3400 \mathrm{rpm}$ to $7300 \mathrm{rpm}$ using two piezoactuators at the bearing bushing and a simple proportional controller.

In this paper, two test rig configurations-hence, with different dynamic behaviors-were simulated showing the instability present in each case. The models consist of a shaft FEM with linear coefficients of stiffness and damping representing the journal bearings. The different conditions of instability are compared through Campbell diagrams, orbits, and run-down simulations. Experimental evidences of oilwhirl and oil-whip are vastly discussed in the literature, mainly by the works of Muszynska [11, 12]. The experimental measurements which motivated this work are also presented and compared with the simulated results.

Therefore, the investigation of the fluid-induced instability in different conditions (here obtained through different test rig configurations) and its detectability in the design stage are the main contribution of this paper.

\section{Materials and Methods}

Two test rig configurations were simulated to compare the different conditions of instability; the finite element models (FEM) used are presented in Figure 1, and details of both configurations are found in Table 1.

Configuration A (Figure 1(a)) is the same from the works of Castro et al. [24] and Mendes et al. [29]. It contains a shaft 


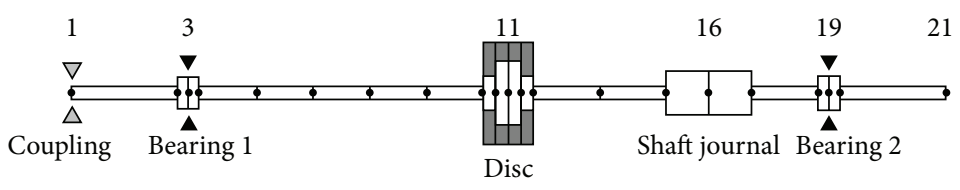

(a)

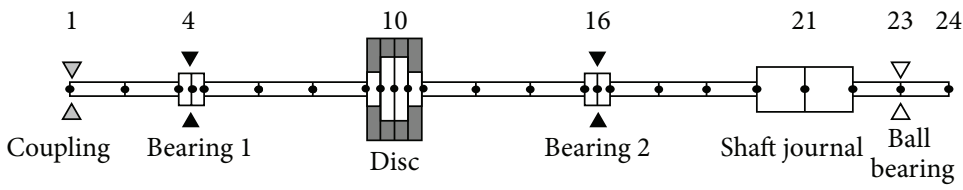

(b)

FIGURE 1: Finite element models: (a) configuration A; (b) configuration B.

TABLE 1: Details concerning both test rig configurations.

\begin{tabular}{lc}
\hline Shaft material & Steel SAE 1030 \\
Shaft diameter & $12 \mathrm{~mm}$ \\
Shaft length & $800 \mathrm{~mm}(\mathrm{~A})-820 \mathrm{~mm}(\mathrm{~B})$ \\
Disc material & Steel SAE 1020 \\
Disc diameter & $95 \mathrm{~mm}$ \\
Disc width & $47.5 \mathrm{~mm}$ \\
Shaft journal material & Steel SAE 1020 \\
Shaft journal diameter & $40 \mathrm{~mm}$ \\
Shaft journal width & $80 \mathrm{~mm}$ \\
Coupling coefficients & $K_{y y}=K_{z z}=1 \mathrm{e} 5 \mathrm{~N} / \mathrm{m}$ and \\
& $K_{y z}=K_{z y}=0 \mathrm{~N} / \mathrm{m}$ \\
Ball bearing coefficients & $K_{y y}=K_{z z}=1 \mathrm{e} 10 \mathrm{~N} / \mathrm{m}$ and \\
Journal bearings radial clearance & $K_{y z}=K_{z y}=0 \mathrm{~N} / \mathrm{m}$ \\
Journal bearings diameter & $90 \mu \mathrm{m}$ \\
Journal bearings width & $30 \mathrm{~mm}$ \\
Lubricant & $20 \mathrm{~mm}$ \\
\hline
\end{tabular}

supported by two hydrodynamic bearings symmetrically placed $600 \mathrm{~mm}$ from each other (nodes 3 and 19). It also contains a disc placed at the shaft mid span (nodes 9 to 13) and a journal at $62 \mathrm{~mm}$ of the first bearing (nodes 15 to 17). The connection between the end of the shaft and the WEG motor is made through a coupling (node 1) modeled by constant linear stiffness coefficients.

Configuration B (Figure 1(b)) consists of a shaft supported by three bearings. Two journal bearings are placed $350 \mathrm{~mm}$ from each other (nodes 4 and 16) and $103 \mathrm{~mm}$ from the right end of the shaft, where there is the motor coupling (node 1). The third bearing is a ball bearing at $305 \mathrm{~mm}$ from the second journal bearing (modeled by constant linear stiffness coefficients at node 23). In this configuration, the disc lays between the journal bearings (nodes 8 to 12) and the shaft journal at $105 \mathrm{~mm}$ before the ball bearing (nodes 20 to 22).

As it can be seen in Figure 1, the FEM model of configuration A was discretized in 21 nodes; while configuration B was

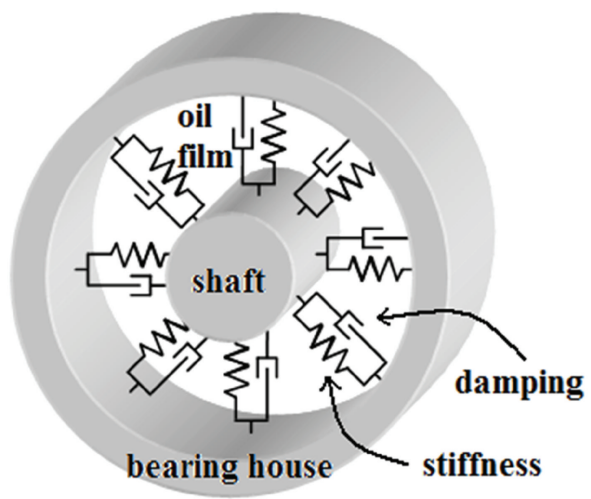

FIGURE 2: Model of the journal bearings.

discretized in 24 nodes. The position of the journal bearings is marked by black triangles, the ball bearing by a white triangle, and the coupling by a grey triangle.

The FEM matrixes used in the flexible rotor models were the classic Euler-Bernoulli beam matrixes for rotating shafts (i.e., including gyroscopic effect), as presented in Nelson and McVaugh [25] and here reproduced in the appendix. The equation of motion is given in (1), where $\Omega$ is the rotational speed, $\mathbf{M}$ is the mass matrix, $\mathbf{G}$ is the gyroscopic matrix, $\mathbf{K}$ is the stiffness matrix, and $\mathbf{C}$ is the damping matrix (proportional to $\mathbf{K}$ by a factor of $2 \times 10^{-4}$ according to Santana et al. [30]). Besides, the matrix $\mathbf{M}$ is obtained from the sum of two matrices (2): the rotational mass matrix $\mathbf{M}_{\mathbf{R}}$ and the translational mass matrix $\mathbf{M}_{\mathrm{T}} \cdot \mathbf{F}(t)$ is the external forces vector, in this case, due to an unbalanced mass; $\mathbf{q}$ is the generalized coordinate vector, with two translational and two rotational degrees of freedom (d.o.f.) for each node:

$$
\begin{gathered}
\mathbf{M} \ddot{\mathbf{q}}(t)+(\mathbf{C}-\Omega \mathbf{G}) \dot{\mathbf{q}}(t)+\mathbf{K q}(t)=\mathbf{F}(t), \\
\mathbf{M}=\mathbf{M}_{\mathbf{T}}+\mathbf{M}_{\mathbf{R}} .
\end{gathered}
$$

The journal bearings are modeled by equivalent coefficients of stiffness and damping (Figure 2), added to the corresponding d.o.f. at the bearings location in the stiffness and 
damping matrixes of the system, $\mathbf{K}$ and $\mathbf{C}$, respectively. The speed dependent coefficients are evaluated from Machado $[16,17,31]$ by the solution of the Reynolds equation (3) using finite volume method:

$$
\frac{\partial}{\partial r}\left(h^{3} \frac{\partial p}{\partial r}\right)+\frac{\partial}{\partial x}\left(h^{3} \frac{\partial p}{\partial x}\right)=6 \mu \Omega \frac{\partial h}{\partial r}+12 \mu \frac{\partial h}{\partial t} .
$$

In (3), $x$ is axial coordinate, $r$ is the circumferential coordinate, $\mu$ is the viscosity of the fluid, $h$ is the fluid film thickness, $p$ is the pressure, and $t$ is the time. From the fluid film thickness, both the linear coefficients (damping and stiffness) are calculated through the perturbation method. The pressure distribution is evaluated from Reynolds equation depending on the fluid film thickness expression. The reaction forces of the bearing can be obtained from the integration of pressure distribution. These forces are functions of the displacements and the instantaneous journal center velocities in direction $y$ and $z$. Initially, the equilibrium position $\left(y_{0}, z_{0}\right)$ of the shaft inside the bearing is found depending on the rotational speed. In this step, the term $\partial h / \partial t$ is not considered. Afterwards, the complete Reynolds equation (3) is solved again considering small deviations around the equilibrium position, $\Delta y$ and $\Delta z$. At this point, a Taylor series expansion yields to (4), where the coefficients are partial derivatives evaluated at the equilibrium position $\left(y_{0}, z_{0}\right)$ as given by (5):

$$
\begin{gathered}
F_{y}=F_{y_{0}}+K_{y z} \Delta z+K_{y y} \Delta y+C_{y z} \Delta \dot{z}+C_{y y} \Delta \dot{y}, \\
F_{z}=F_{z_{0}}+K_{z z} \Delta z+K_{z y} \Delta y+C_{z z} \Delta \dot{z}+C_{z y} \Delta \dot{y}, \\
K_{y z}=\left(\frac{\partial F_{y}}{\partial z}\right)_{0}, \\
C_{y z}=\left(\frac{\partial F_{y}}{\partial \dot{z}}\right)_{0} .
\end{gathered}
$$

Lund [15] pointed out that the solution of the Reynolds equation should be solved simultaneously with the dynamic equation of the rotor; still, for practical purposes it can be assumed that the vibration amplitude is small enough to allow substituting the fluid film forces by their gradients around the steady-state eccentricity for a given rotational speed; that is, the forces become proportional to the displacement (stiffness coefficients) and velocity (damping coefficients). Lund [32] also states that, although the coefficients definition is only valid for infinitesimal amplitudes, comparisons with exact solutions have shown that the coefficients approach may be applied for amplitudes as large as nearly forty percent of the bearing clearance. It is also recommended that the eccentricity ratio lies below 0.6-0.7.

In this work, the simulations performed presented much lower amplitude levels than the limit stated by Lund [32], except when the stability limit is reached. It is remarked here that the interest of the analysis performed is in finding out the instability threshold of the system and not the rotor behavior once it is unstable.

The coefficients behavior dependence on the rotational speed is shown in Figure 3 (stiffness coefficients) and Figure 4 (damping coefficients). The eccentricities of the journal bearings used in both configurations are presented in
Figure 5, which shows that below $10 \mathrm{~Hz}$, the bearings operate with eccentricity ratio less than 0.6 , justifying the linearized coefficients behavior in this range.

It should be noticed that, although the coefficients are speed dependent, the model of the entire system (rotor and bearings) is linear, what implies that the system thresholds of instability when performing run-up and run-down simulations are the same.

It is important to point out that the observance of the instability threshold in a standard rotordynamic analysis (frequency domain) is quite interesting from the practical point of view, being here the main focus of this paper.

\section{Results and Discussion}

As stated before, in journal bearings supported rotors, two kinds of forward self-excited vibrations are present: oil-whirl and oil-whip [11]. As vastly discussed in the literature, oilwhip is an unstable vibration which occurs near twice the first critical speed of the rotor, occurring when oil-whirl coincides with the natural frequency of the shaft. This phenomenon was simulated and experimentally observed in a test rig used in previous works $[24,29]$, here called configuration A. However, when the test rig configuration was changed (configuration B) a different kind of instability was observed in the simulations and in the experimental setup. In order to better understand the different instability mechanisms, a series of simulations was proposed, which is presented in this survey.

3.1. Homogeneous Solution. From the solution of the homogeneous part of (1) it is possible to obtain the Campbell and modal damping diagrams and the natural modes of the system. Figure 6 presents the Campbell and modal damping diagrams for both configurations. In the Campbell diagram, when the rotational speed curve (1x line) crosses one of the natural frequencies of the rotor, there is a resonance region and the rotational speed, at this point, is called critical speed. Hence, a critical speed is clearly observed in configuration A (Figure 6(a)) at approximately $26.6 \mathrm{~Hz}$ while in configuration B (Figure 6(c)) close to $75 \mathrm{~Hz}$. When simulating a shaft finite element model containing journal bearings modeled by linear coefficients of stiffness and damping, two natural frequencies (one for each bearing) can be found near half the rotational speed of the rotor (Figures 6(a) and 6(c)).

In fact, these frequencies show up due to the effect of the journal bearings stiffness coefficients representing the fluid film. The presence of such frequencies allows the linear model to represent the fluid-induced vibrations phenomena with a very good agreement with experimental observations of rotor dynamic behaviors. Muszynska [11] simulated a flexible rotor supported by one rigid bearing and one journal bearing, modeled by the modal parameters of the first bending mode. Three eigenvalues were encountered, with two of them related to the first bending modes and one with the frequency (imaginary part) close to the oil-whirl frequency. The author noted that the real part of this third eigenvalue predicts the threshold of instability. In the words of Muszynska [11], this 


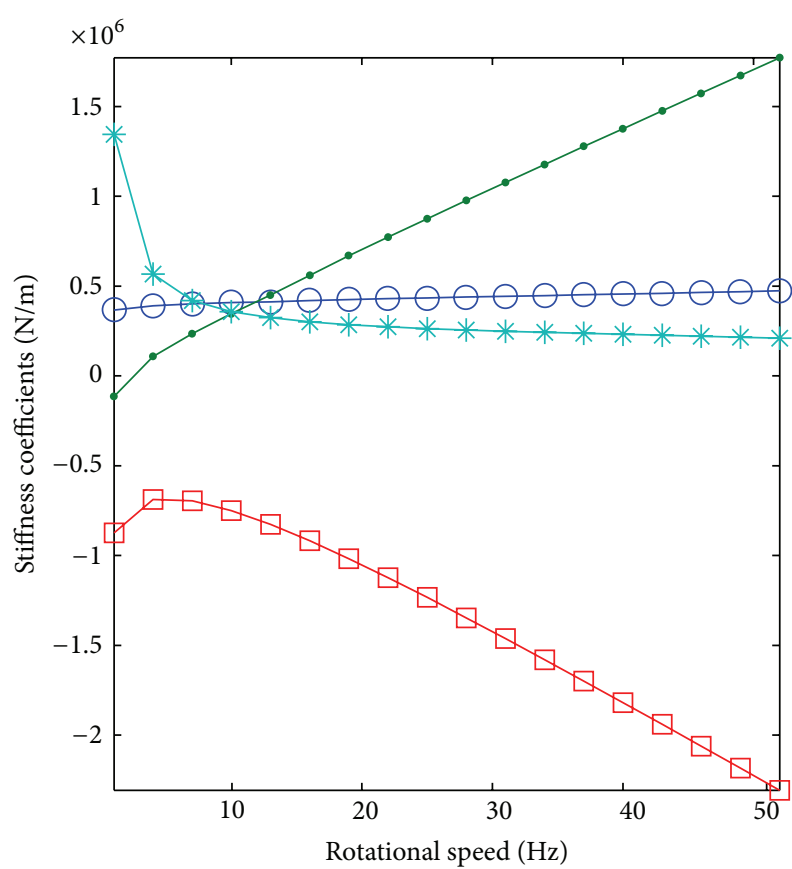

(a)

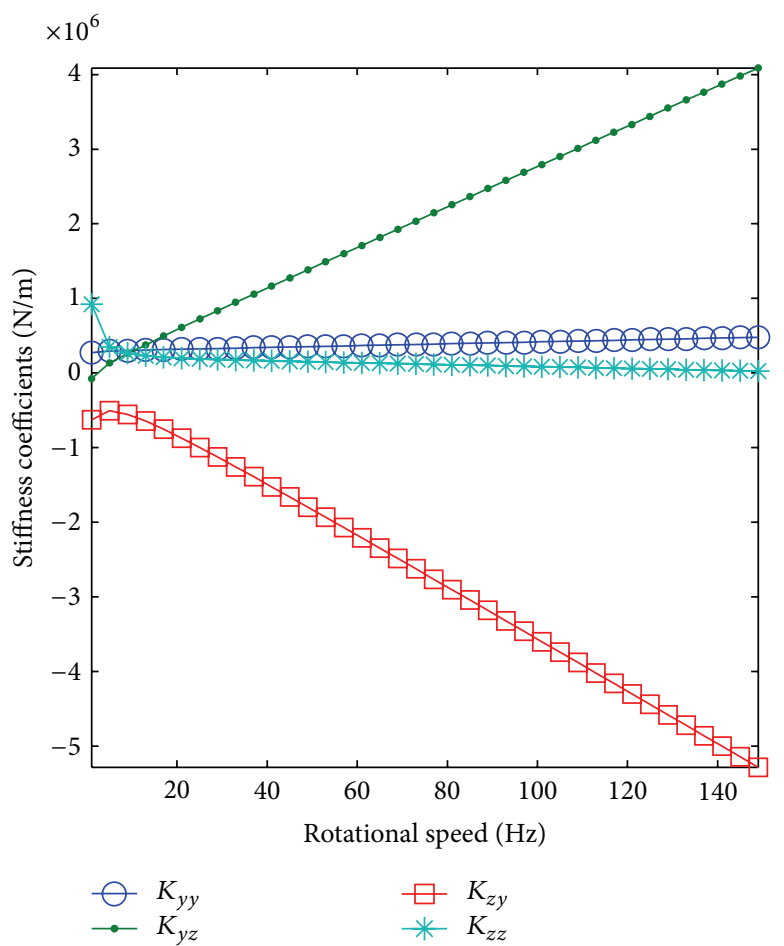

(c)

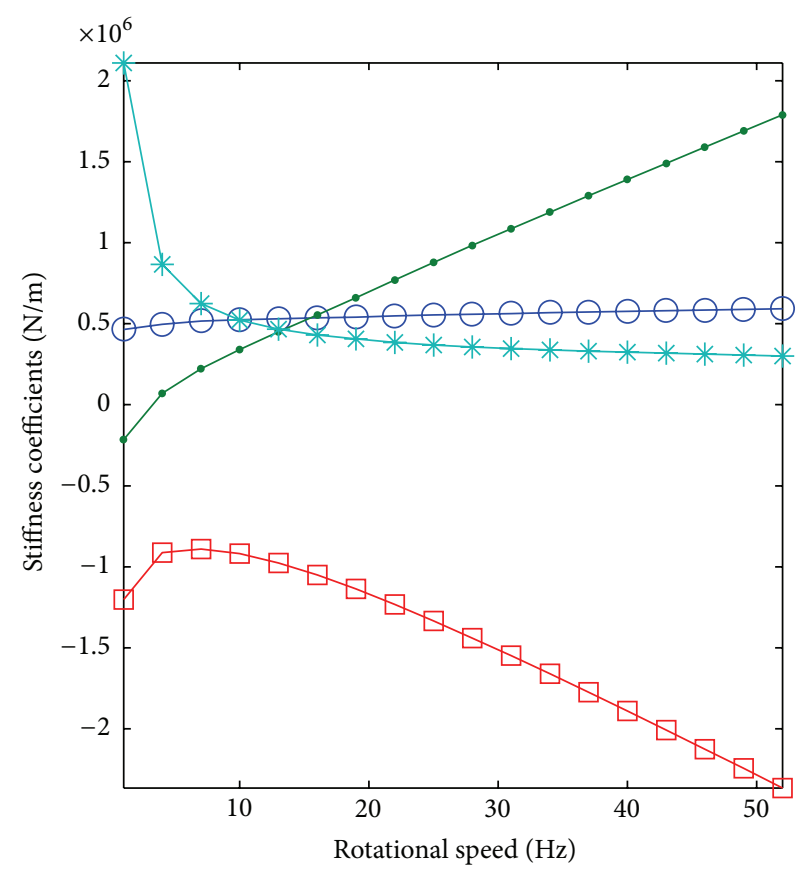

(b)

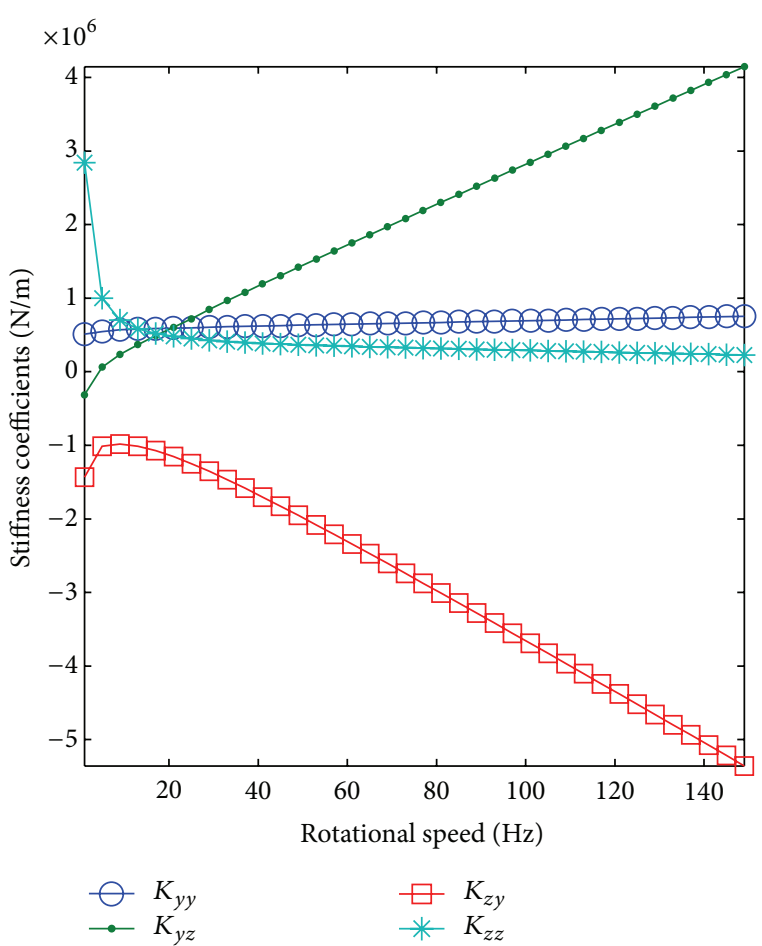

(d)

Figure 3: Equivalent coefficients of stiffness for the journal bearings: (a) bearing 1 in configuration A; (b) bearing 2 in configuration A; (c) bearing 1 in configuration $\mathrm{B}$; $(\mathrm{d})$ bearing 2 in configuration $\mathrm{B}$.

is an "unconventional fluid/solid interaction-related natural frequency of the rotor/bearing system," hereinafter denoted as fluid frequencies. As it was shown, in the finite element models of the rotors considered in this paper, there were two fluid frequencies, one related to each journal bearing.
Moreover, Figure 6(a) shows one of the fluid frequencies crossing the first natural frequency of the rotor when the rotational speed is of approximately $53.6 \mathrm{~Hz}$, what means to excite the first mode of the rotor at a rotational speed nearly twice the critical speed of the rotor. It can also be 


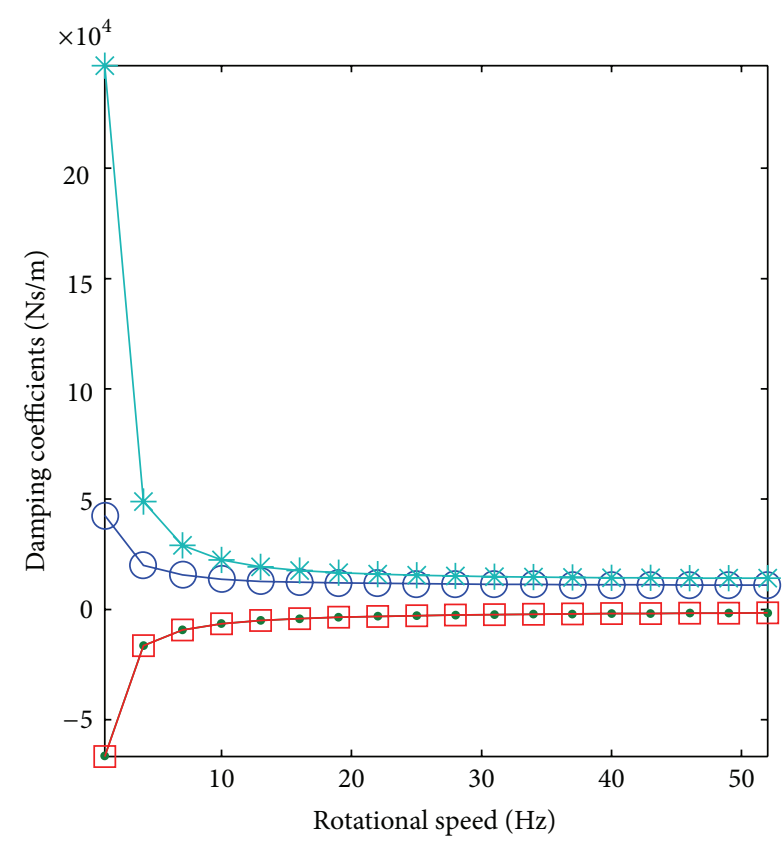

(a)

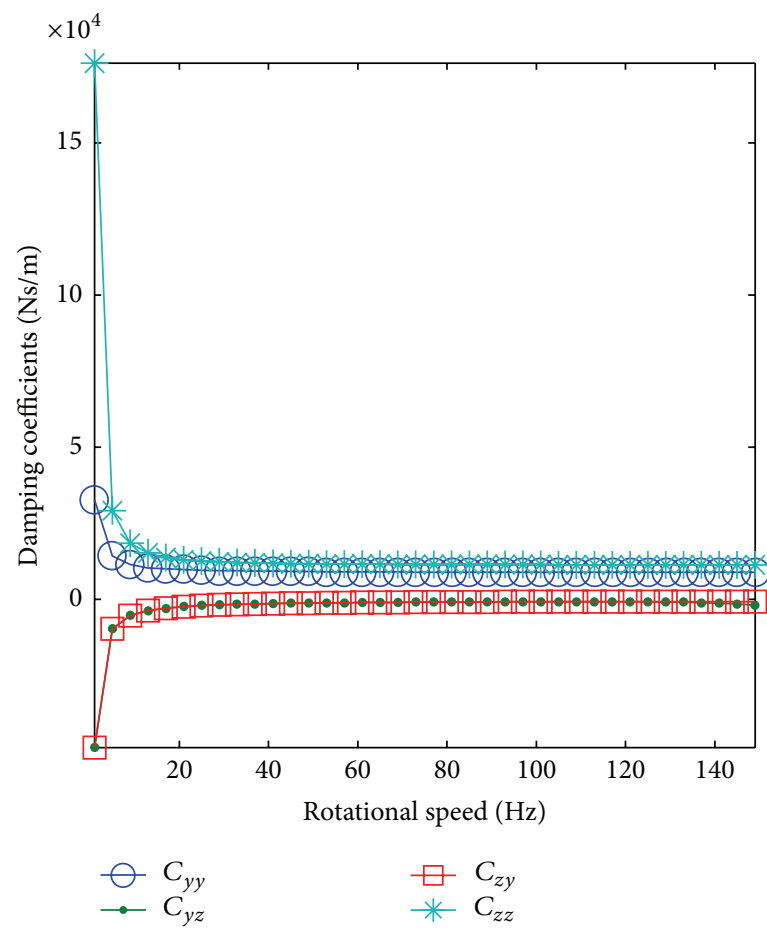

(c)

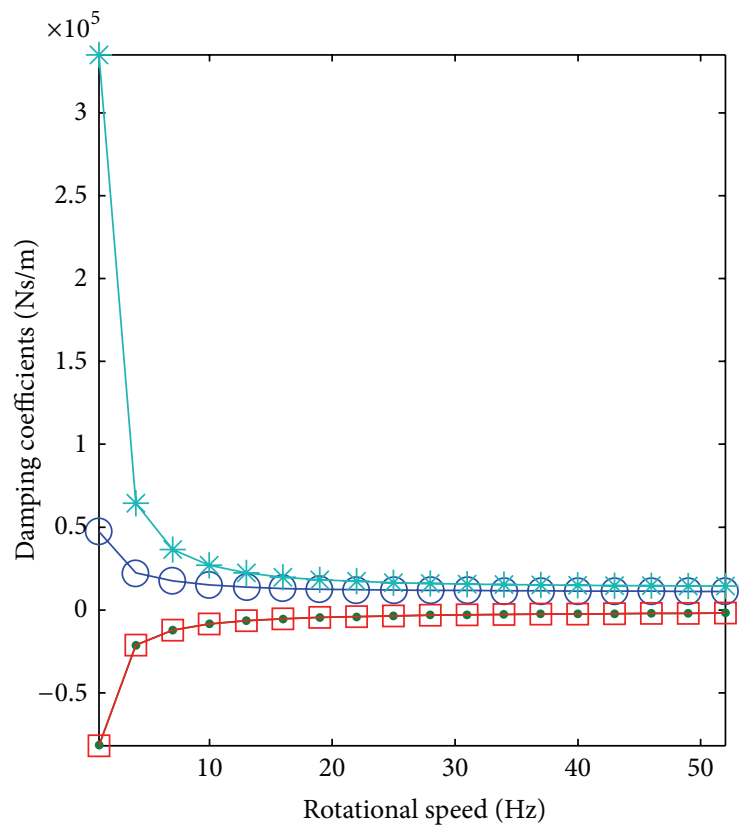

(b)

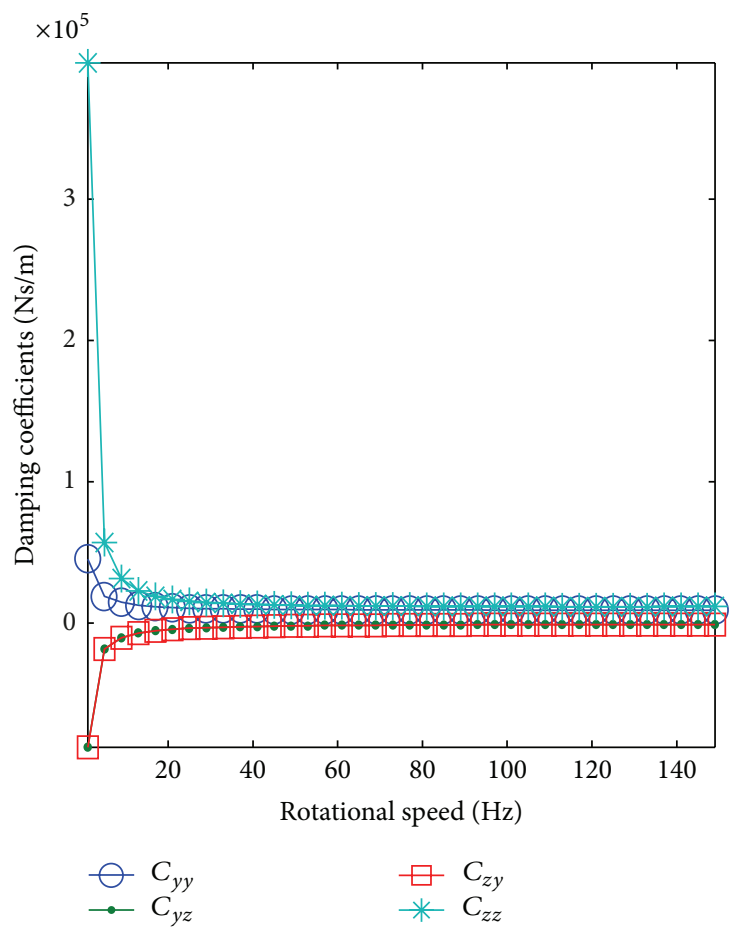

(d)

FIGURE 4: Equivalent coefficients of damping for the journal bearings: (a) bearing 1 in configuration A; (b) bearing 2 in configuration A; (c) bearing 1 in configuration $\mathrm{B}$; $(\mathrm{d})$ bearing 2 in configuration $\mathrm{B}$.

seen, in the modal damping diagram of configuration A (Figure 6(b)), that near twice the first natural frequency of the rotor $(53.6 \mathrm{~Hz})$ one of the fluid frequencies damping assumes a negative value, meaning that the system became unstable after the frequency of $49 \mathrm{~Hz}$. This instability threshold occurs very close to the oil-whip frequency, as it can be seen in the Campbell diagram. Once this instability threshold is achieved, its frequency does not change anymore, because the rotor enters in the oil-whip instability and it develops a high level vibration with a frequency component near its natural frequency, which does not change even if the rotor accelerates [11]. During oil-whip the bearing vibration amplitude is 


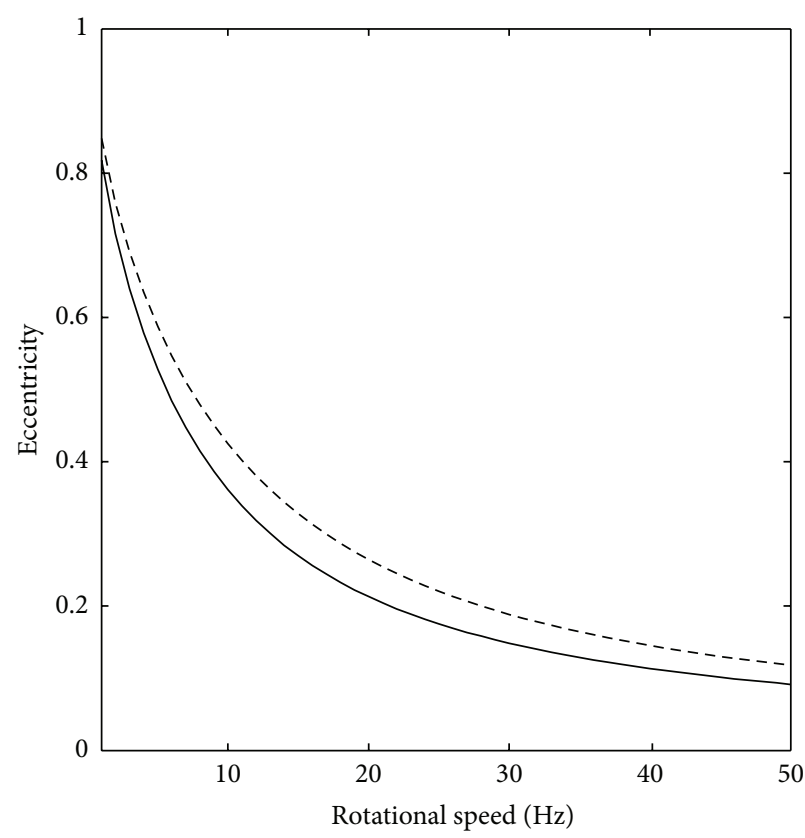

Bearing 1A

-- Bearing $2 \mathrm{~A}$

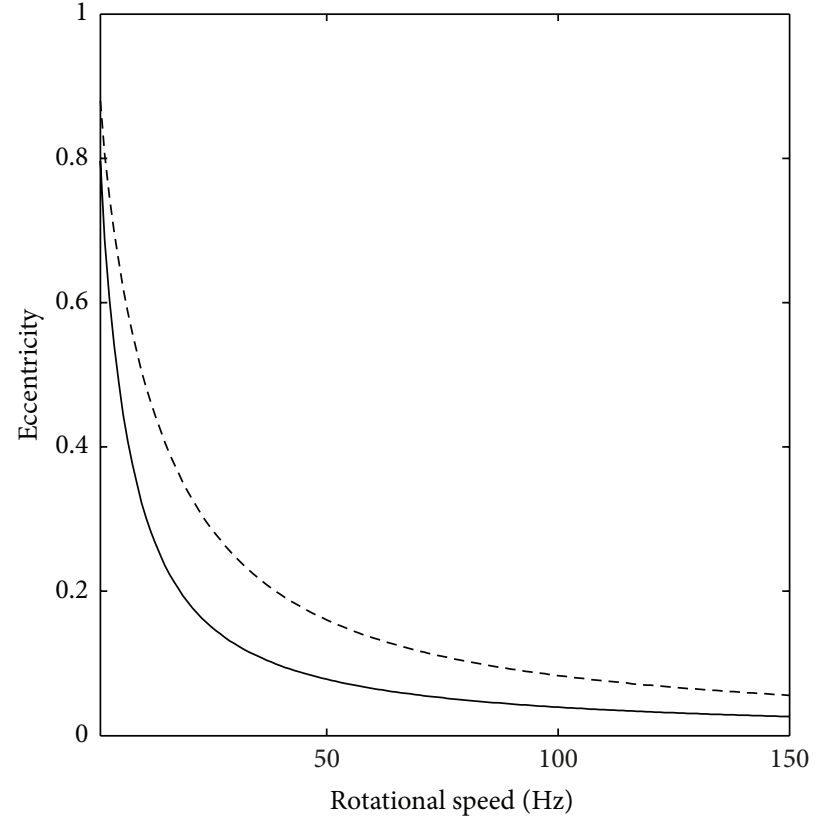

- Bearing 1B

- - Bearing 2B

(a)

(b)

FIGURE 5: Journal bearings eccentricity: (a) configuration A; (b) configuration B.

limited by the bearing clearance, but the rotor develops a much higher vibration level, once its natural frequency is being excited, as previously mentioned.

Analogously, Figure 6(c) shows the fluid frequency crossing the first natural frequency $(75 \mathrm{~Hz})$ at the rotational speed of $150 \mathrm{~Hz}$, which characterizes an oil-whip frequency in this case. However, the modal damping diagram of configuration B (Figure 6(d)) shows that this configuration has an instability threshold at $101 \mathrm{~Hz}$, which is much lower than the expected oil-whip instability, what suggests that a different kind of fluid-induced instability occurs. The behavior of the fluid frequency that gets unstable did not become constant as it did in configuration A, pointing to the oil-whirl as the instability cause, although it is interesting to point out that near the expected oil-whip frequency $(150 \mathrm{~Hz})$ the tendency of being constant is observable, suggesting that oil-whip instability would happen at that frequency if the rotor did not get unstable sooner for another reason.

The mode shapes of configuration $A$ are shown in Figure 7, and in Figure 8, for configuration B, respectively. Figures 7(a) and 7(b) give the natural mode of the rotor at the rotational speed of $40 \mathrm{~Hz}$, corresponding respectively to the fluid frequencies of $21.83 \mathrm{~Hz}$ and $20.85 \mathrm{~Hz}$-regarding to the hydrodynamic bearings (whirl precession). Figures $7(\mathrm{c})$ and 7(d) bring the forward $(25.74 \mathrm{~Hz})$ and backward $(27.01 \mathrm{~Hz})$ natural modes of the rotor when the rotational speed is $40 \mathrm{~Hz}$.

The mode shapes of the fluid frequencies for configuration B (Figures 8(a) and 8(b)) show that each fluid frequency corresponds to each of the journal bearings due to the fact that in each mode shape one of the bearings presents a high displacement; such effect is not so clear in configuration A (Figure 7(a)).

Up to this point, it was shown that through the homogeneous solution of the system equation, configuration $\mathrm{A}$ presents oil-whip instability, but configuration B presents an instability threshold lower than expected, suggesting that oil-whirl dominates the unbalance response, defining the threshold of instability.

3.2. Forced Response. In order to obtain a better understanding of the instability mechanism, run-down simulations were performed for both configurations (Figure 9). Configuration A was simulated from $50 \mathrm{~Hz}$ to $3 \mathrm{~Hz}$, once the analysis showed the system became unstable at $49 \mathrm{~Hz}$, and configuration $\mathrm{B}$ from $150 \mathrm{~Hz}$ to $3 \mathrm{~Hz}$, because the modal damping diagram (Figure 6(d)) indicates that instability starts at $101 \mathrm{~Hz}$, but the Campbell has evidence that oil-whip would happen nearly at $150 \mathrm{~Hz}$. In both cases, a deceleration of $1 \mathrm{~Hz} / \mathrm{s}$ was used.

Remark. The reason why run-down simulations were used instead of run-ups is related to the instability sensitivity of the linear model used for the journal bearings. It was noticed in run-up simulations that, even though the rotor was unstable after the instability threshold, the vibration amplitude rises in a very slow shape. Consequently, a run-down simulation may be set to start in a rotor unstable condition, with large vibration amplitudes, overcoming the run-up simulation limitation. Hence, run-down simulations are suitable to the study of fluid-induced instability simulations in cases where, like in this work, the entire system model is linear (recalling that 


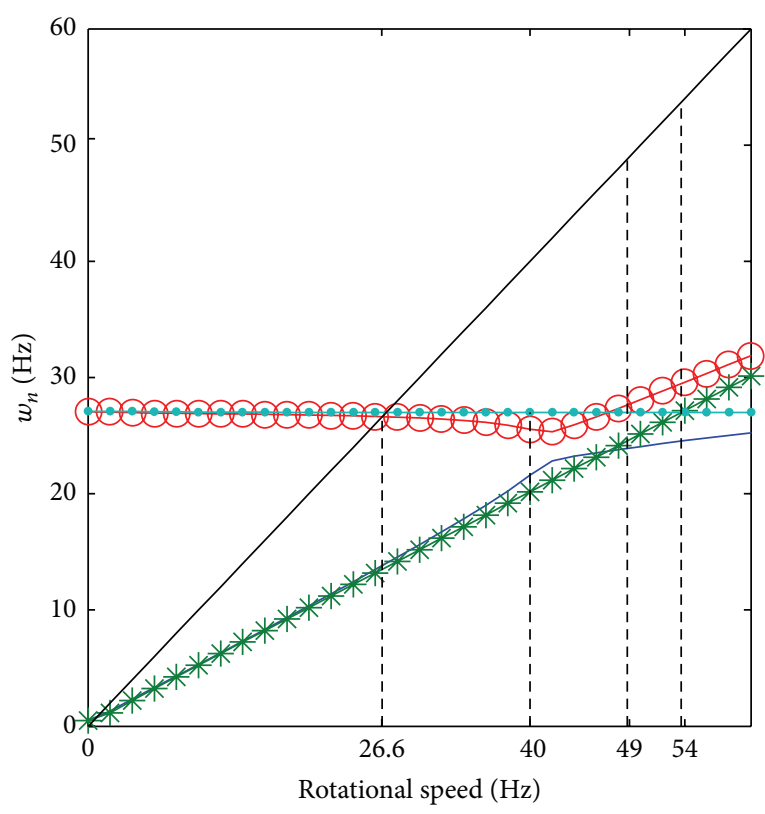

(a)

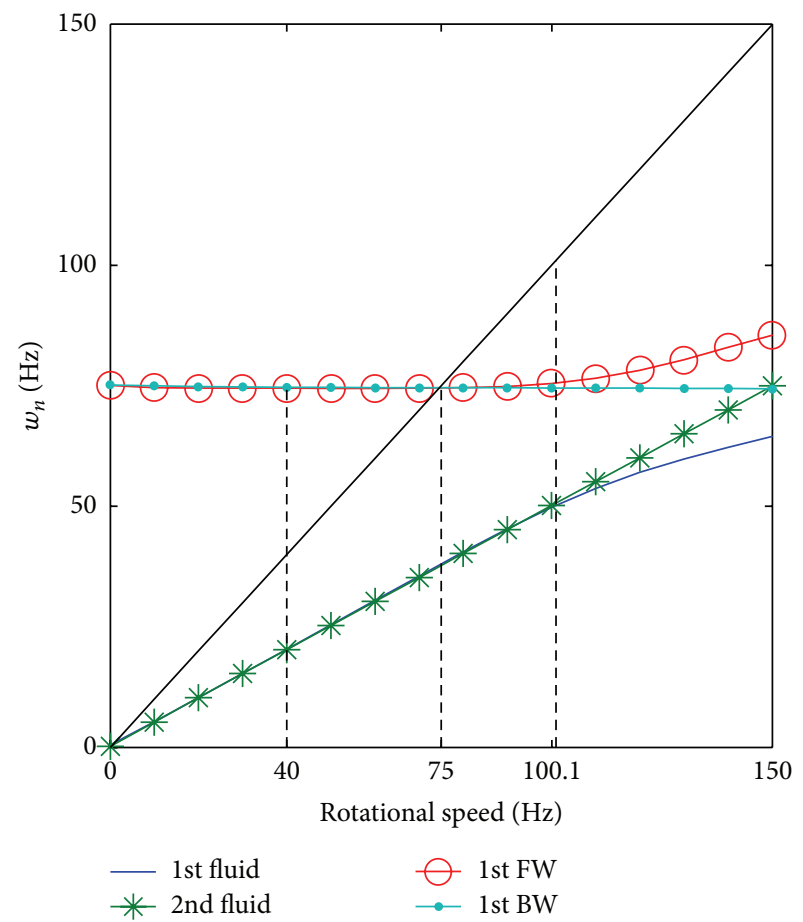

(c)

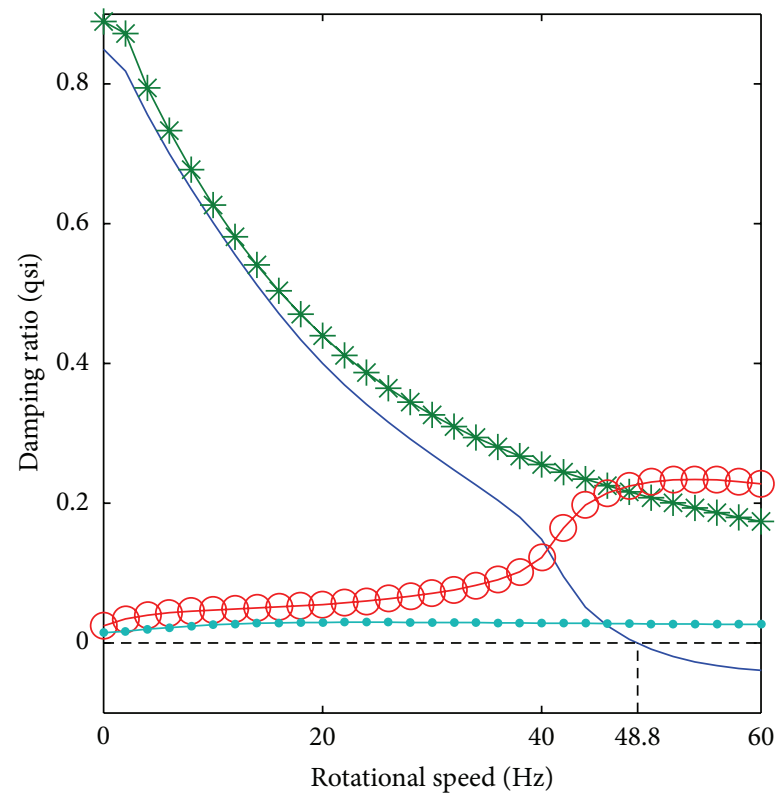

(b)

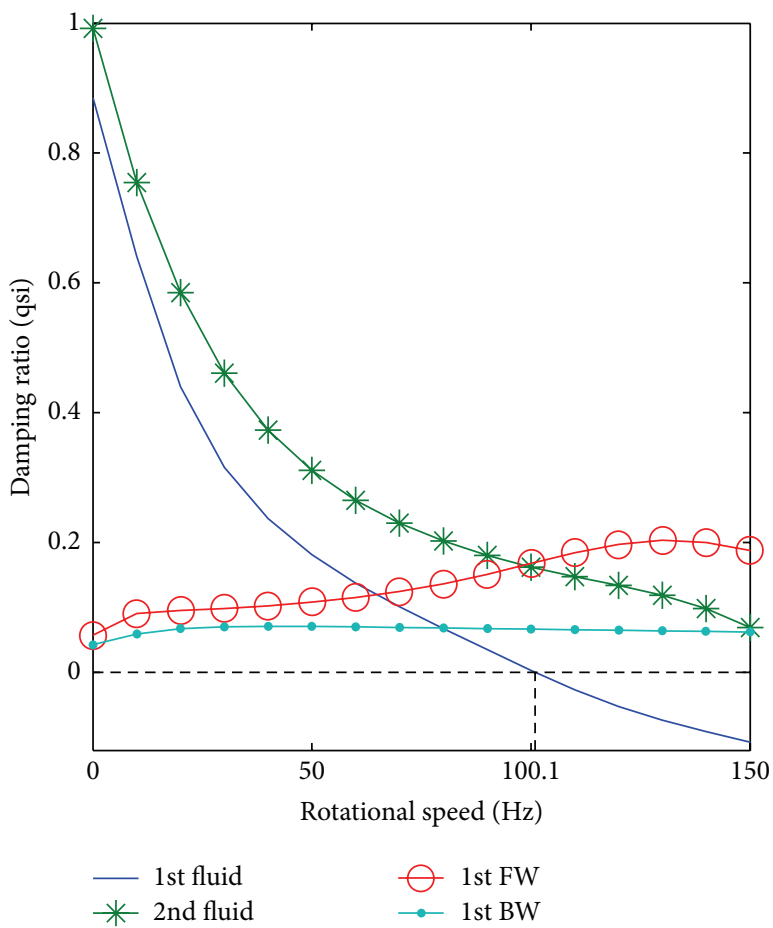

(d)

FIgURE 6: (a) Campbell diagram of configuration A; (b) modal damping of configuration A; (c) Campbell diagram of configuration B; (d) modal damping of configuration B.

the journal bearings were modeled using a linear coefficients approach), and the same instability thresholds are obtained either for run-up or run-down simulations. It should also be noticed that the journal bearings nodes vibration is limited by the bearing radial clearance. The interaction between the journal and the housing wall is not in the scope of this paper. Thereby, a simple approach was used: when the vibration amplitude gets higher than the radial clearance, the angular position of the shaft inside the bearing is kept constant and its amplitude is reduced to the clearance value. The disadvantage of this approach is that harmonic components showed up in the waterfall diagrams. Hence, their influence should be disregarded in the analysis.

Figures 9(a) and 9(c) show the time response for the rundown in the first journal bearing of each configuration, where it is clear that the systems were unstable once the stability 


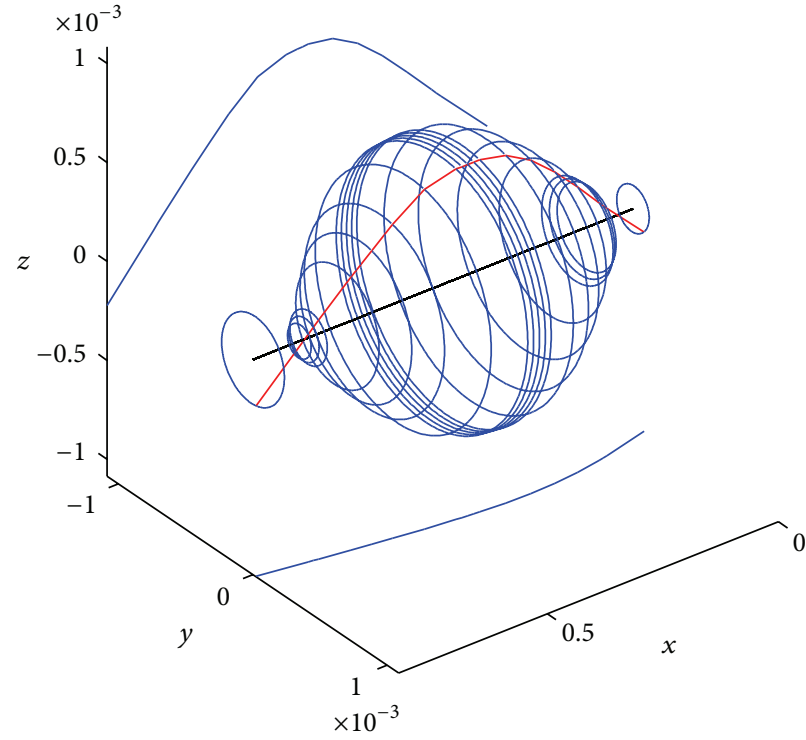

(a)

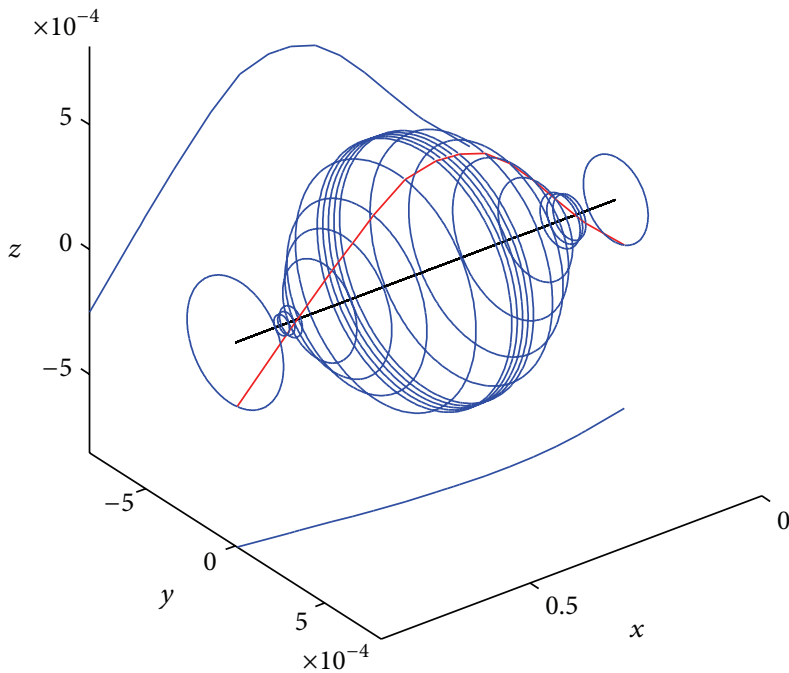

(c)

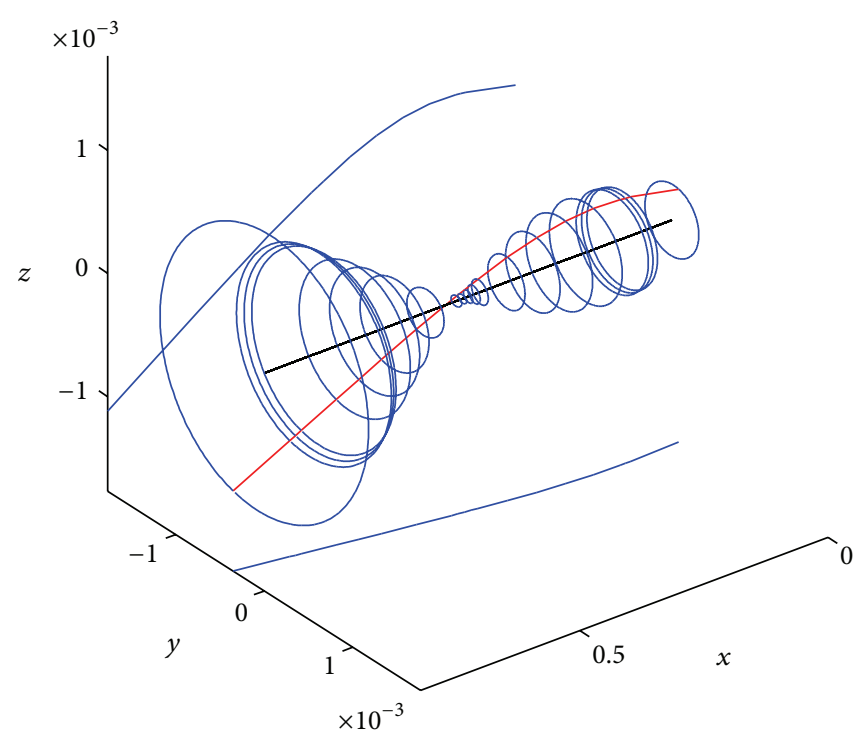

(b)

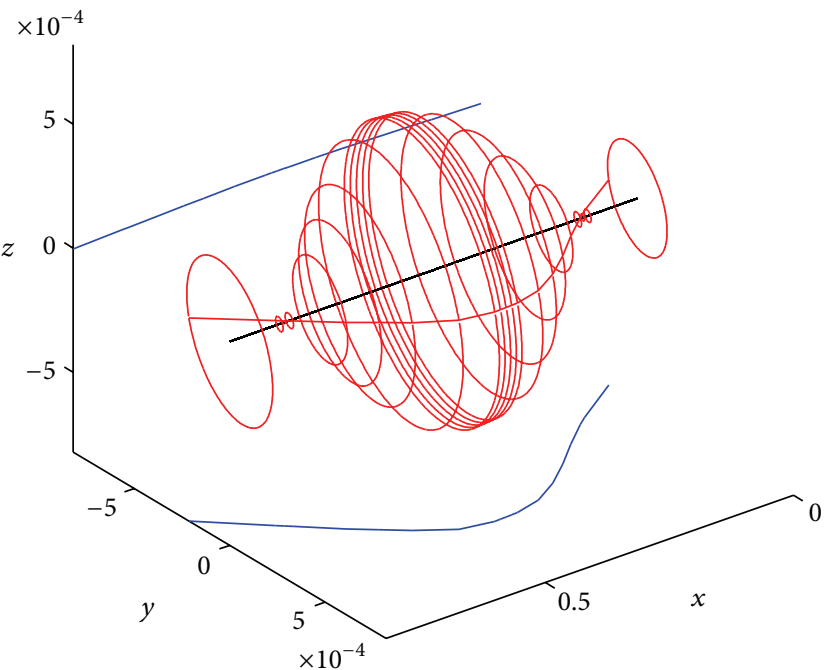

(d)

Figure 7: Natural modes of configuration A for a rotational speed of $40 \mathrm{~Hz}$ : (a) bearing 2 fluid frequency at $21.83 \mathrm{~Hz}$; (b) bearing 1 fluid frequency at $20.85 \mathrm{~Hz}$; (c) first forward flexural natural frequency at $25.74 \mathrm{~Hz}$; (d) first backward flexural natural frequency at $27.01 \mathrm{~Hz}$.

thresholds were crossed. The self-centering effect of the shaft due to unbalance (reduction of the orbit amplitude after the critical speed) and the self-centering effect of the bearing can also be noticed.

Figures $9(\mathrm{~b})$ and $9(\mathrm{~d})$ contain the waterfall diagrams correspondent to Figures 9(a) and 9(c), respectively. Oilwhirl did not show up in configuration A (Figure 9(b)). The system presents only the unbalance response until oil-whip takes place, when the modal damping of the fluid frequency crosses the zero. In real rotors, it can be seen that the orbit of the shaft inside the bearings presents a deployment due to a subharmonic component at half the rotational speed (i.e., oil-whirl); and when the rotor rotational speed has a small increment and crosses the instability threshold, the oil-whip becomes dominant [11]. Figure 10 presents the orbits and the spectra of the first bearing in several constant rotational speeds (dashed lines in Figure 9(a)), before the critical speed $(10 \mathrm{~Hz})$, at the critical speed $(26.6 \mathrm{~Hz})$, between the critical speed and the instability threshold $(35 \mathrm{~Hz})$, and at $48.8 \mathrm{~Hz}$ (close to the instability), and no deployment can be seen, which demonstrate a limitation of the linear model once this phenomenon was observed in the nonlinear model used in the work of Castro et al. [24], although the instability threshold presented good agreement. The large orbit seen in Figure 9 (a) at $48 \mathrm{~Hz}$ is a transient effect of the system going out of the instability region (near $48.8 \mathrm{~Hz}$ ), once this result was obtained from a run-down simulation as previously mentioned.

In the case of configuration $\mathrm{B}$, the time response of the run-down (Figure 9(c)) also shows the instability of the rotor, 


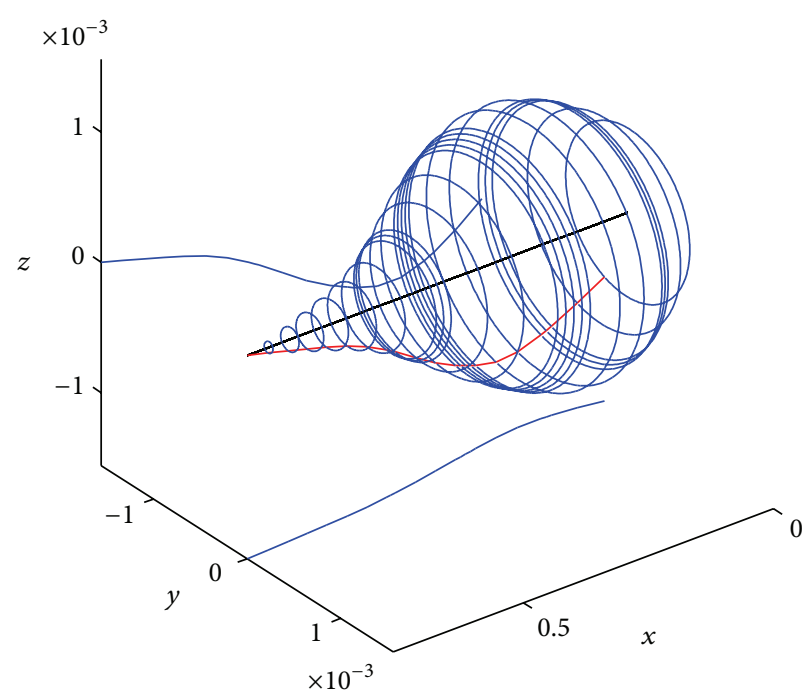

(a)

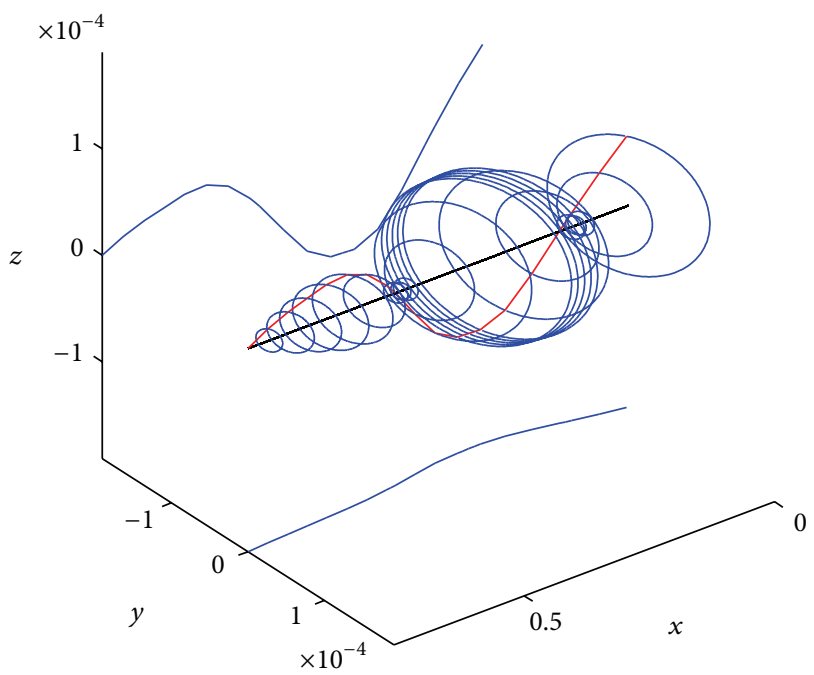

(c)

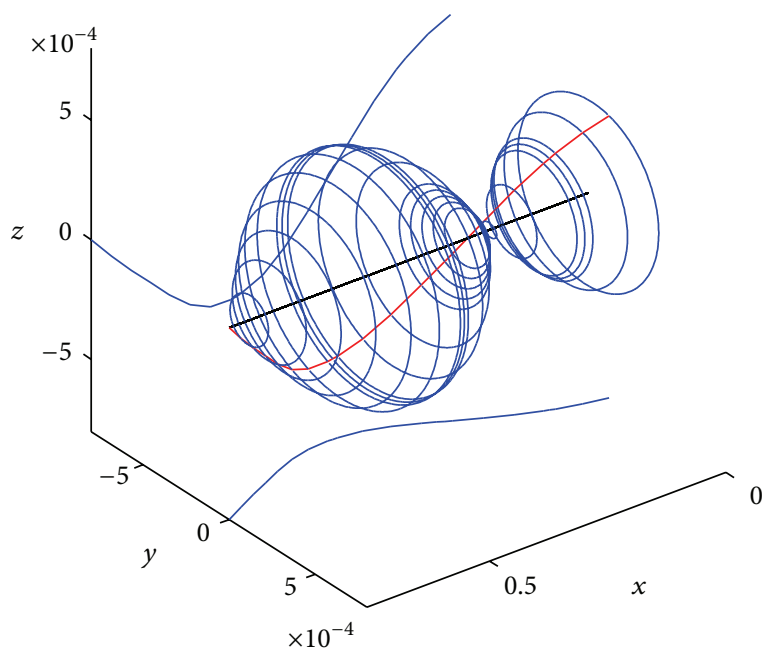

(b)

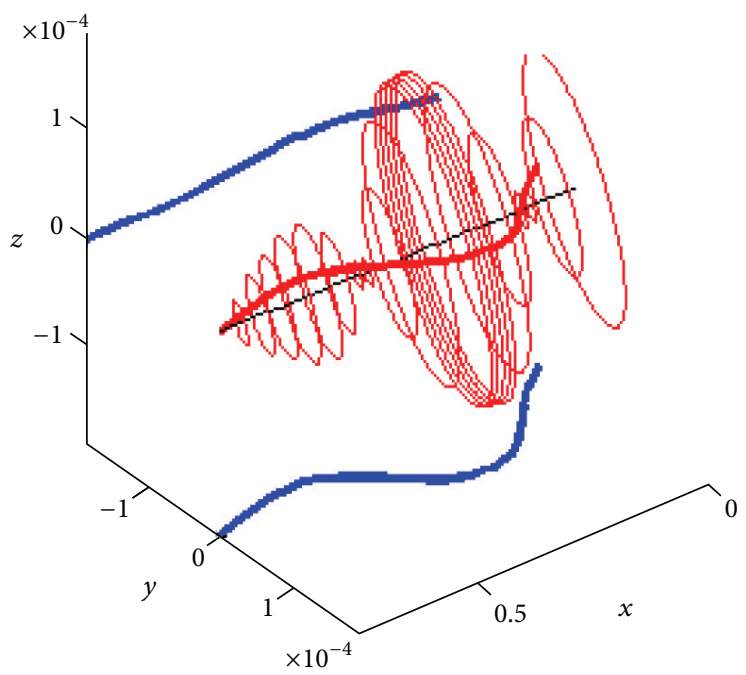

(d)

Figure 8: Natural modes of configuration B for a rotational speed of $40 \mathrm{~Hz}$ : (a) bearing 2 fluid frequency at $20.94 \mathrm{~Hz}$; (b) bearing 1 fluid frequency at $21.85 \mathrm{~Hz}$; (c) first forward flexural natural frequency at $74.89 \mathrm{~Hz}$; (d) first backward flexural natural frequency at $74.882 \mathrm{~Hz}$.

when the orbit amplitude is limited by the bearing clearance. However, in the waterfall diagram it can be seen that near the instability threshold $(101 \mathrm{~Hz})$ oil-whirl rises and starts to cause an unstable vibration. It is possible to observe it because as the rotational speed changes, the unstable harmonic component of the vibration also changes, being close to $46 \%$ of the rotational speed until nearby $150 \mathrm{~Hz}$, when oil-whip is expected to occur even though the system was already unstable because of oil-whirl. Thereby, in configuration B, instead of oil-whip, oil-whirl was the responsible for driving the system unstable.

Constant rotational speed simulations were also performed for two cases in configuration $\mathrm{B}$, at $99 \mathrm{~Hz}$ and close to the instability limit at $101 \mathrm{~Hz}$; the orbits of the first bearing and the frequency spectrum are presented in Figure 11. The experimental results, which have motivated this survey, are also shown in Figure 11 overlaid to the simulated results to highlight the differences. All measurements were made using 3300 RAM inductive sensors from Bently Nevada.

At the rotational speed of $99 \mathrm{~Hz}$ (gray curves in Figures 11(a) and 11(b)) only the unbalance effect appears, but as the rotational speed was increased to $101 \mathrm{~Hz}$, the orbit deployment appears (Figure 11(c) in gray), indicating the presence of oil-whirl as it can be seen in the frequency spectrum (Figure 11(d) in gray).

The experimental threshold of instability is slightly shifted to $103.4 \mathrm{~Hz}$. Therefore, the first difference between experiment and simulation is in the constant rotational speeds measured, $100.4 \mathrm{~Hz}$ and $103.4 \mathrm{~Hz}$, which shows that the model is a little bit more conservative. The orbit shapes (black curves in Figures 11(a) and 11(c)) are considerably different from the simulated results, and the reason is the presence of many 


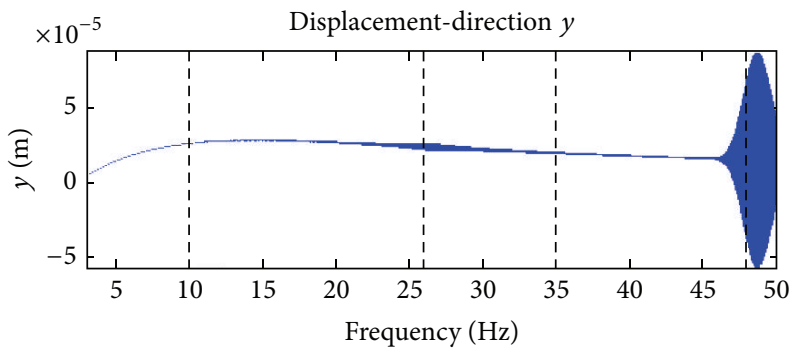

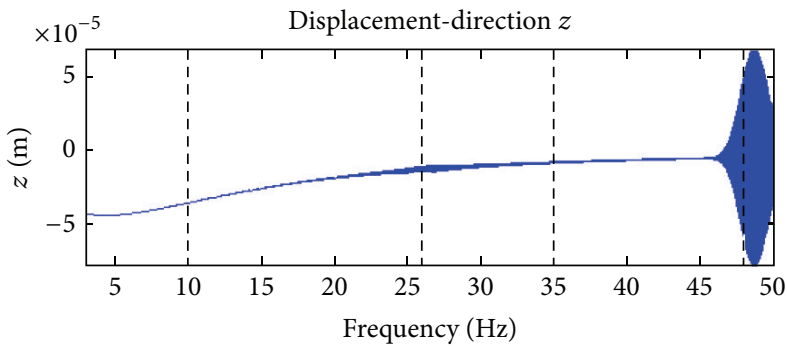

(a)
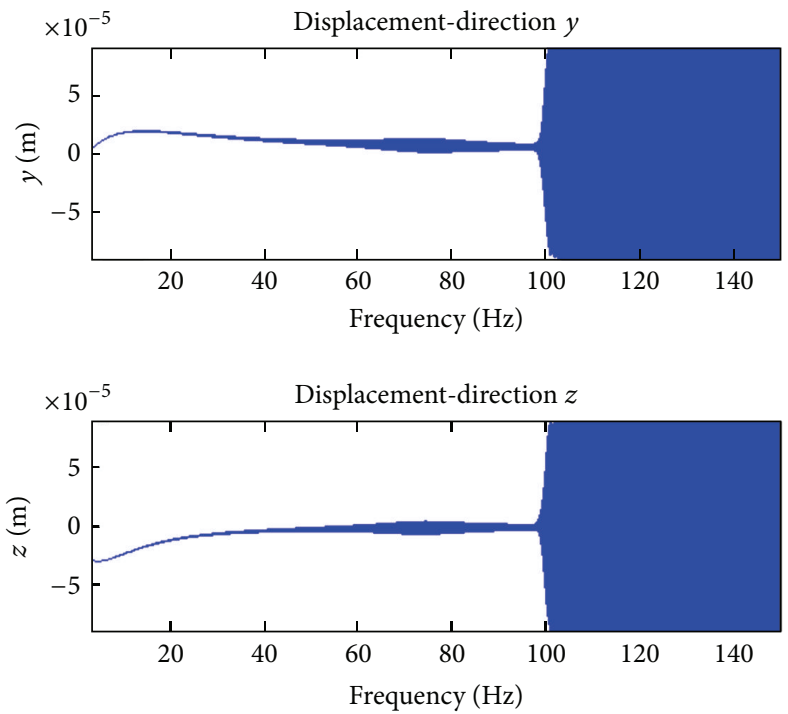

(c)

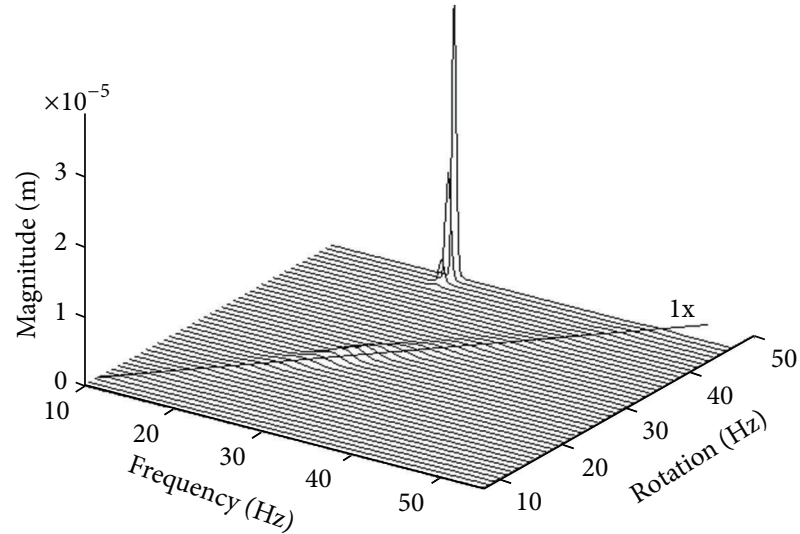

(b)

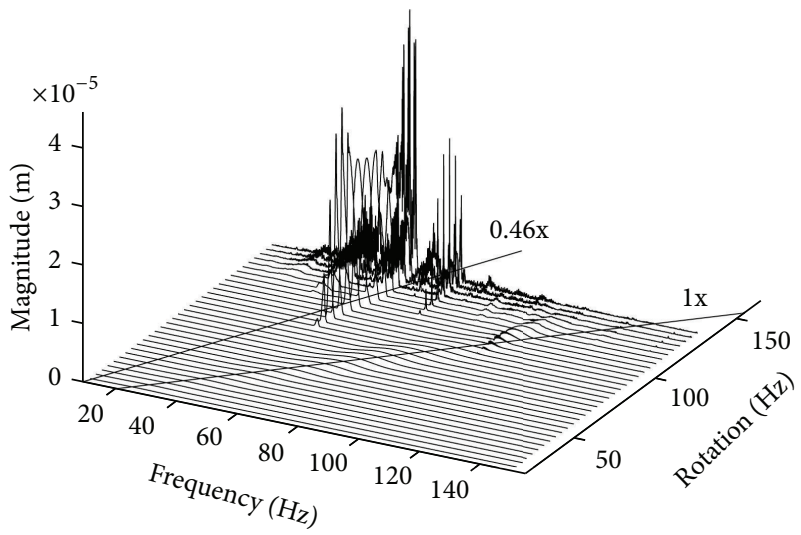

(d)

FIGURE 9: Run-down simulations: (a) time response of the first bearing in configuration A (see Figure 1); (b) waterfall diagram of the first bearing in configuration $\mathrm{A}$; (c) time response of the first bearing in configuration $\mathrm{B}$; (d) waterfall diagram of the first bearing in configuration B.

harmonics found in the experimental frequency spectra (Figures 11(b) and 11(d) in black). Such harmonics occur due to the ball bearing at the shaft end in configuration $\mathrm{B}$; as the rotor spins and its spheres pass through the lower part of the bearing, where the load is applied, harmonics of the rotational speed are excited and participate in the vibration response. This effect is not present in the simulations once the ball bearing is merely modeled by constant stiffness and damping coefficients (Figure 11(b)). However, the rotational speeds associated with the threshold of instability are very close and the oil-whirl components in the spectra present about the same amplitudes obtained by the simulation response (Figure 11(d)).

Therefore, comparing the two different cases, it can be seen that in one case the instability was caused by oil-whirl and, in the other case, by oil-whip. It should be reminded at this point that oil-whirl could exist in a stable condition until it turns to oil-whip, as presented in Castro et al. [24]; such behavior would be expected by a lighter rotor than the ones used in the present survey. Moreover, it was shown here that the instability threshold could be safely estimated when using the linear coefficients approach for journal bearings modeling.

3.3. Eccentricity Analysis. The denominations heavy rotor or light rotor used when talking about horizontal rotors supported on journal bearings are related to the eccentricity of the shaft during operation. The bearing eccentricity is a function of the load applied on each bearing and the bearing 


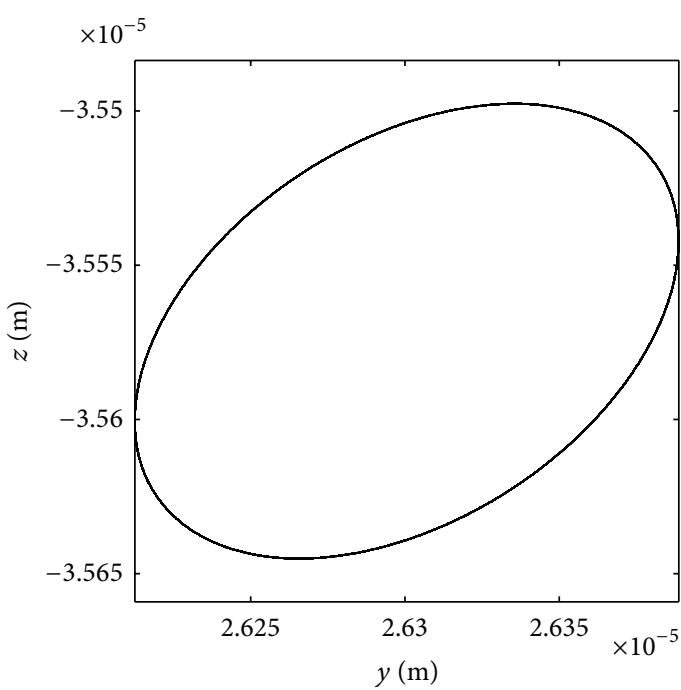

(a)

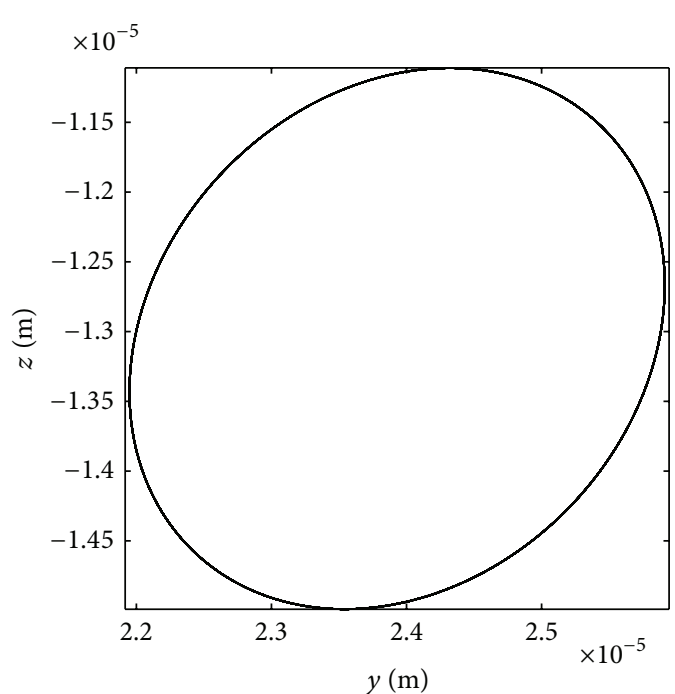

(c)

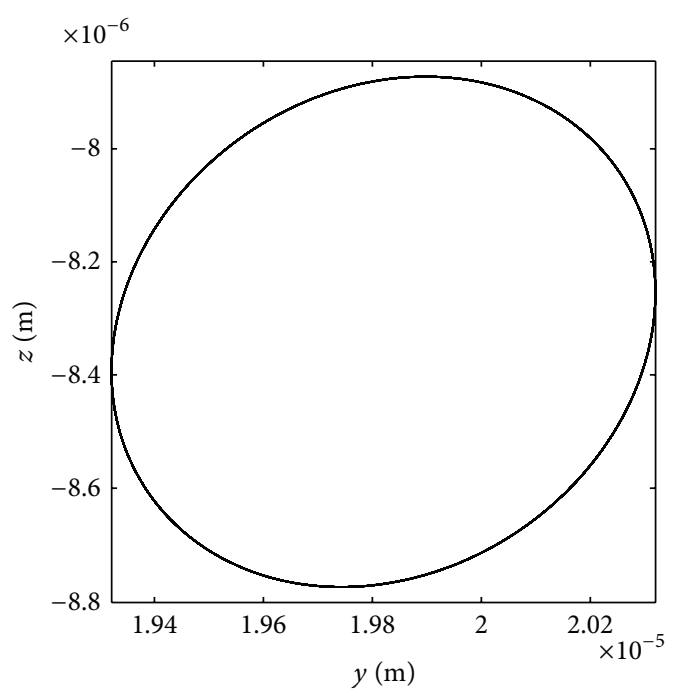

(e)

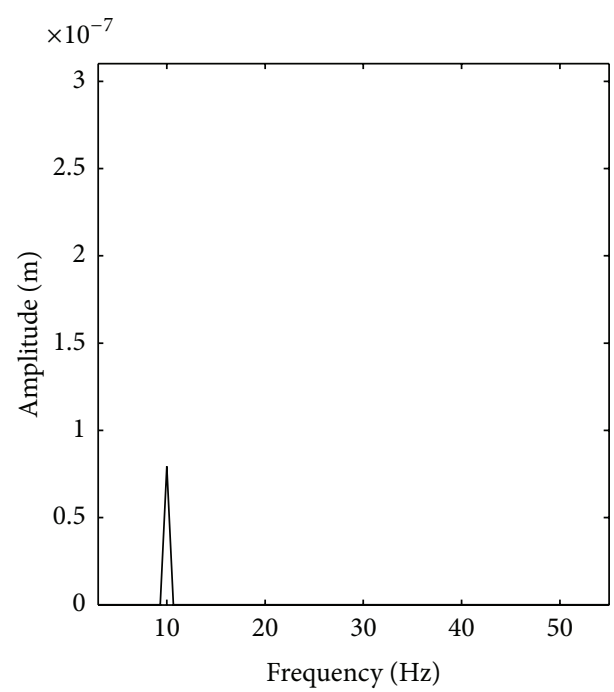

(b)

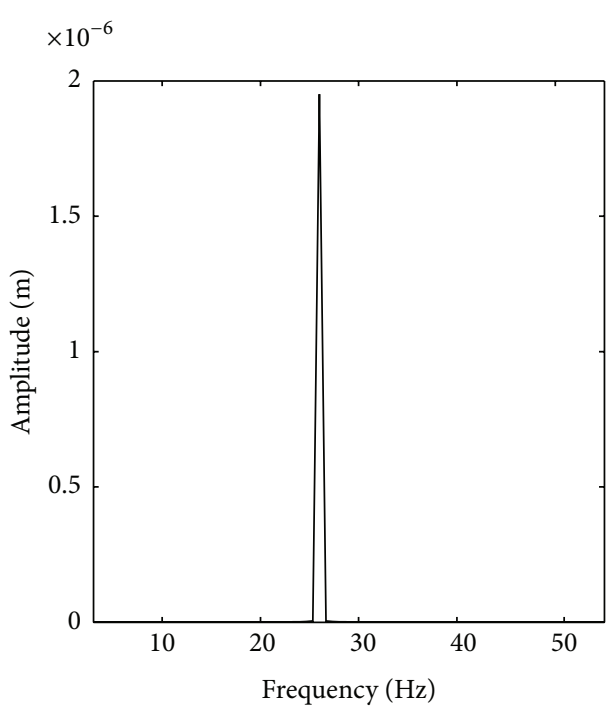

(d)

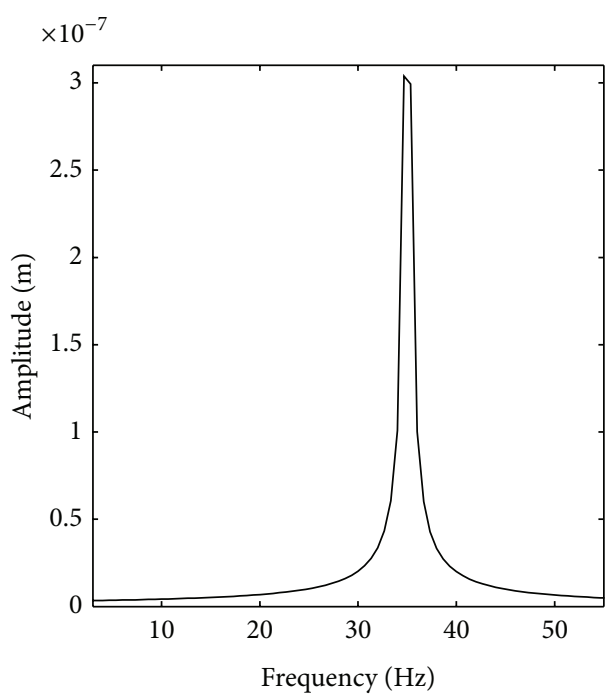

(f)

FIgUre 10: Continued. 


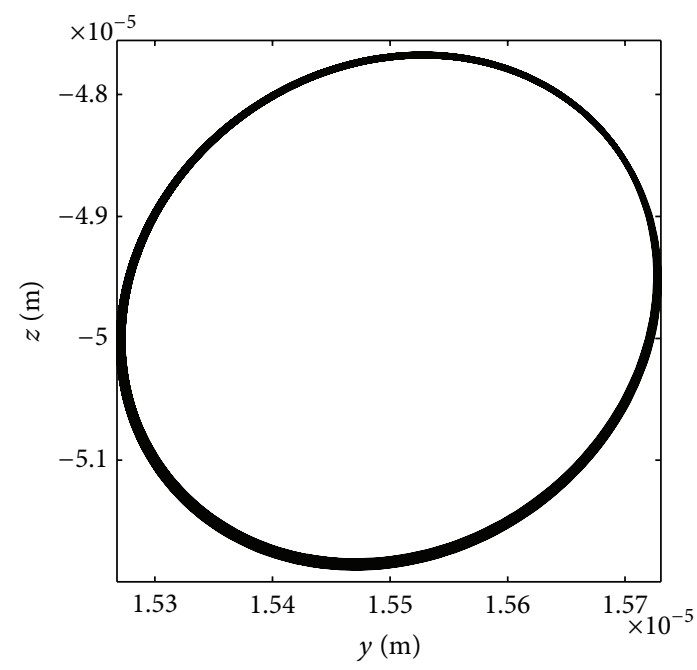

(g)

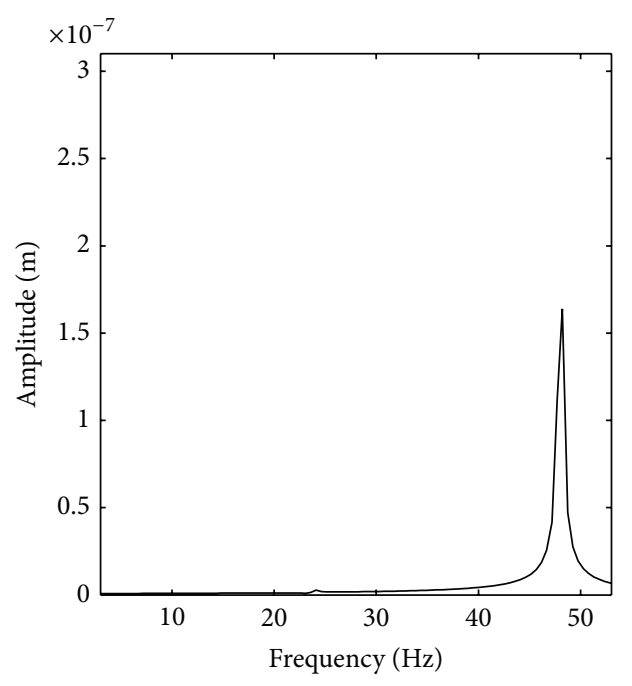

(h)

FIGURE 10: Simulated results of the first bearing in configuration A for constant rotational speeds (see Figure 8(a)): (a) orbit at $10 \mathrm{~Hz}$; (b) frequency spectrum at $10 \mathrm{~Hz}$; (c) orbit at $26 \mathrm{~Hz}$; (d) frequency spectrum at $26 \mathrm{~Hz}$; (e) orbit at $35 \mathrm{~Hz}$; (f) frequency spectrum at $35 \mathrm{~Hz}$; (g) orbit at $48 \mathrm{~Hz}$; (h) frequency spectrum at $48 \mathrm{~Hz}$.

load capacity at each rotational speed. In this sense, the terminology heavy rotor and light rotor refers to the relation between bearing load and load bearing capacity and how it affects the bearing eccentricity. The bearing load is constant and dependent on the geometry of the rotating system; yet, as bearing load capacity is a function of the rotational speed, so is the bearing eccentricity.

When operating at low rotational speeds, a journal bearing pumps a little quantity of oil underneath its journal, resulting in a thin stiff fluid-film and in a high eccentricity; thus, oil-whirl is not present and the rotor is stable.

As the rotational speed increases, the decreasing in the eccentricity and the rising of the attitude angle (tending to 90 degrees) results in the self-centering effect. The thick fluid film causes disequilibrium of the stabilizing forces inside the bearings; the same condition of low eccentricity occurs in vertical or lightly loaded horizontal rotors as they operate nearly centered.

Figure 12 presents the forces acting on the shaft inside the bearing as terms of the stiffness and damping coefficients. In order to maintain stable operation, the dissipative force $\left(F_{z}^{d}\right.$ and $\left.F_{y}^{d}\right)$ must suppress the destabilizing effect of the cross-coupled stiffness $\left(F_{z y}^{s}\right.$ and $\left.F_{y z}^{s}\right)$. However, as the rotational speed increases, the cross-coupled stiffness coefficients increase drastically, while the direct stiffness and the damping coefficients present only small changes (Figures 3 and 4), which causes a reduction of stability and oil-whirl may appear.

If the rotor keeps on accelerating, it will achieve the instability threshold and oil-whirl may become unstable (as in configuration B) or it may give place to oil-whip (as in configuration A).

Consequently, the different behaviors of the instability mechanism in both configurations $\mathrm{A}$ and $\mathrm{B}$ are due to the relation between bearing load and bearing load capacity.
If the rotor has one bearing working in a light rotor condition, such that it became unstable before oil-whirl reaches the natural frequency of the rotor (and turn to oil-whip), then oil-whirl will be the cause of the instability. If the bearings work in a heavy rotor condition (higher eccentricity), then oil-whip will cause the instability at twice the rotor natural frequency. Oil-whirl instability threshold here is considered to be the point where the subsynchronous harmonic is limited only by the bearing clearance; and this effect is observed in the linear models as a negative value associated with the fluidfrequency in the modal diagrams.

Since the same bearings were used in both cases, the load in each case tells which bearing is more unstable. The loads for configuration $\mathrm{A}$ are $17.7 \mathrm{~N}$ for the first bearing and $23.1 \mathrm{~N}$ for the second, and configuration $\mathrm{B}$ has $12.5 \mathrm{~N}$ on the first bearing and $26.7 \mathrm{~N}$ on the second. This means that the rotor from configuration $\mathrm{B}$ has a bearing with a much lower eccentricity (less stable) as it can be seen in Figure 5, what explains why the instability mechanism has a different behavior from the previous configuration. In configuration $\mathrm{B}$, oil-whirl became unstable much sooner than the expected oil-whip.

Only for comparison, the load in the ball bearing in configuration $\mathrm{B}$ is $1.46 \mathrm{~N}$; therefore, the sum of the loads of the bearings in each configuration allows observing that both configurations have almost the same weight $(40.8 \mathrm{~N}$ for configuration $\mathrm{A}$ and $40.66 \mathrm{~N}$ for configuration $\mathrm{B}$ ). This fact agrees with the early explanation between how the rotor weight is not the only parameter related to the light/heavy rotor denominations, but it strongly depends on the load applied to each bearing and the bearing load capacity.

\section{Conclusions}

Motivated by experimental results, a survey about the fluidinduced instability mechanism was presented considering 


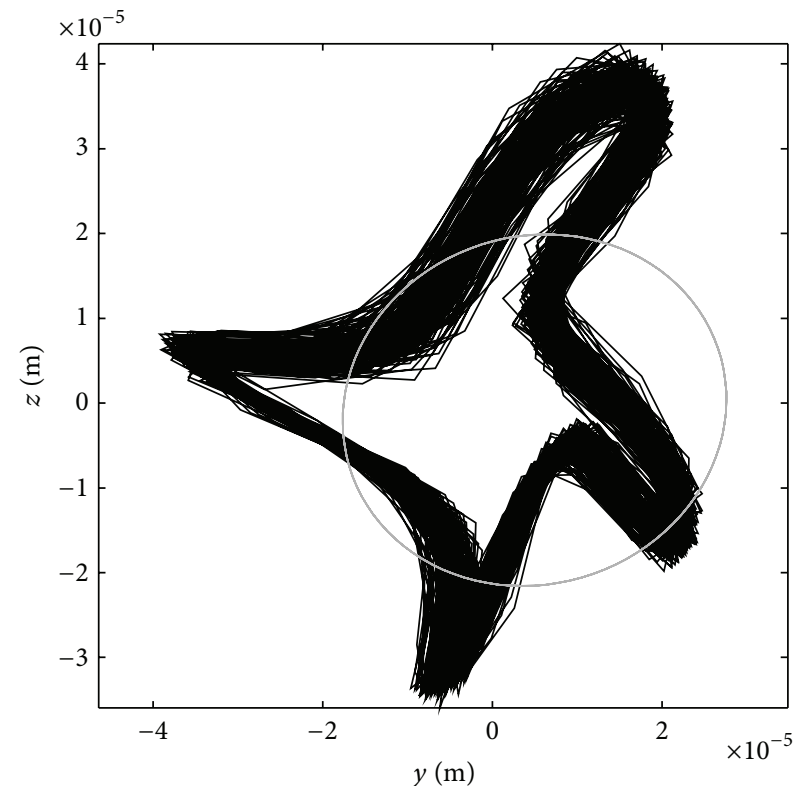

(a)

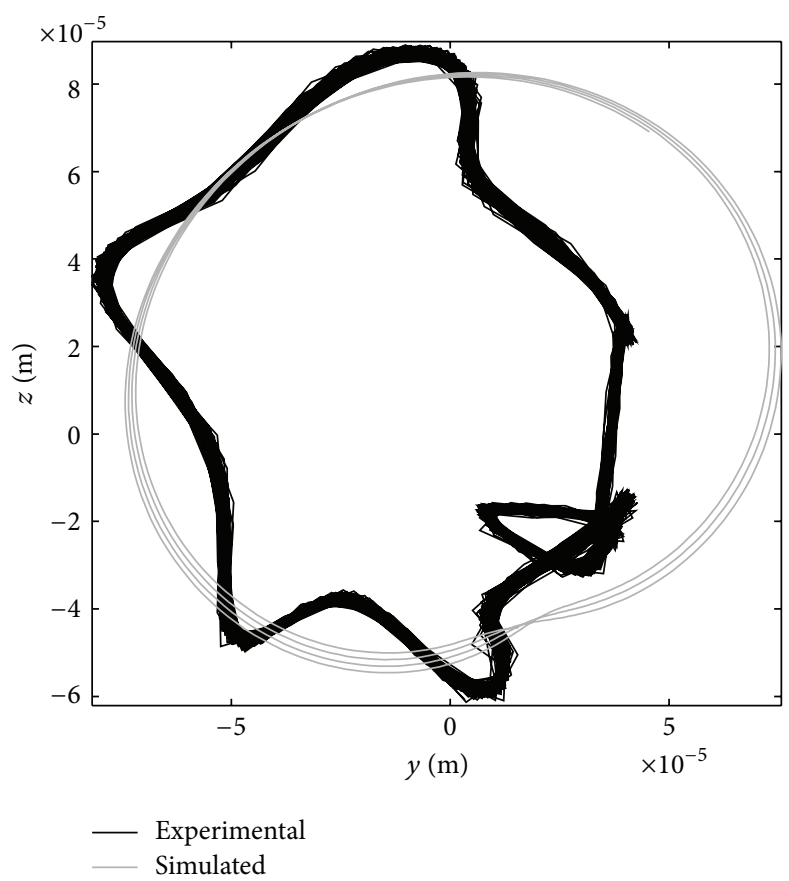

(c)

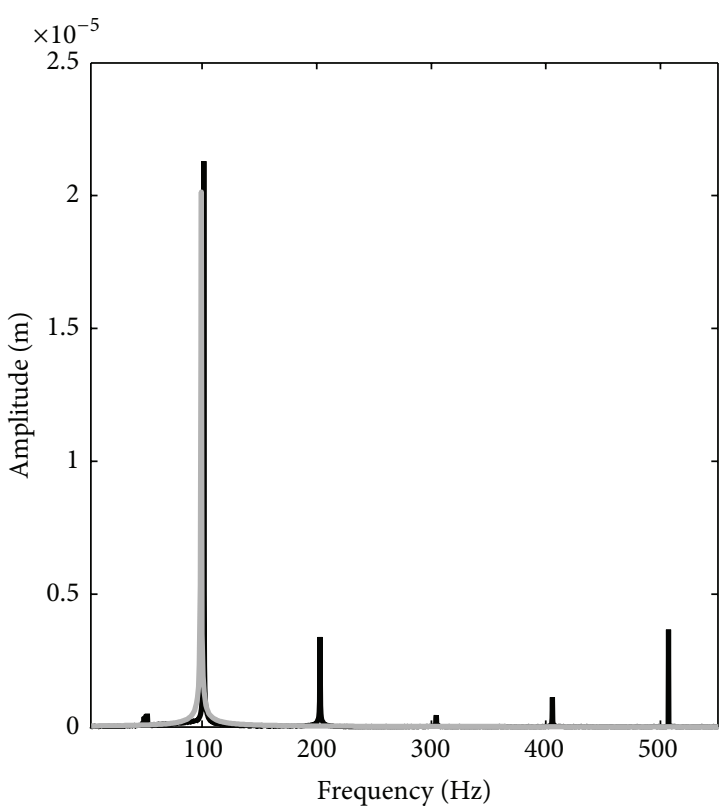

(b)

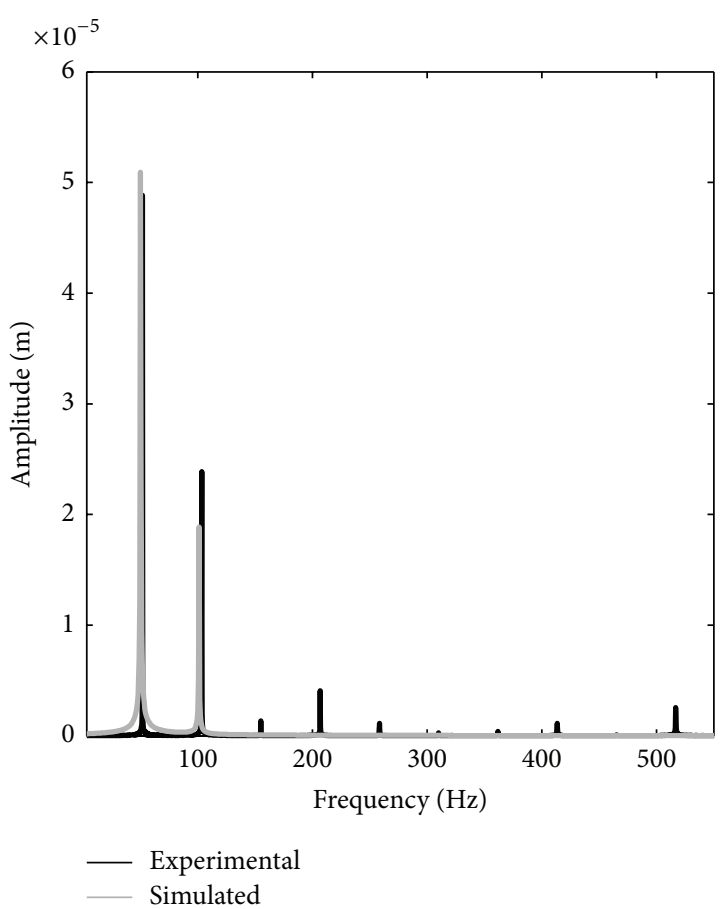

(d)

FIGURE 11: Experimental and simulated results for two conditions with fixed rotational speeds in configuration B: (a) orbits of the first condition (experimental $99 \mathrm{~Hz}$, simulated at $101 \mathrm{~Hz}$ ); (b) frequency spectrum of the first condition (experimental at $99 \mathrm{~Hz}$, simulated at $101 \mathrm{~Hz}$ ); (c) orbits of the second condition (experimental at $101.4 \mathrm{~Hz}$, simulated at $103.4 \mathrm{~Hz}$ ); (d) frequency spectrum of the second condition (experimental at $101.4 \mathrm{~Hz}$, simulated at $103.4 \mathrm{~Hz}$ ).

two different rotor configurations. The hydrodynamic bearings were modeled as linear coefficients of stiffness and damping, evaluated through the solution of the Reynolds equation using a finite-volume method. The first configuration instability threshold is the expected oil-whip frequency; however, in the second configuration, the instability threshold occurs much sooner than expected, being caused by an unstable oil-whirl vibration. The analysis and comparison of both cases were made through Campbell and modal damping diagrams and, afterwards, run-down simulations (waterfall 


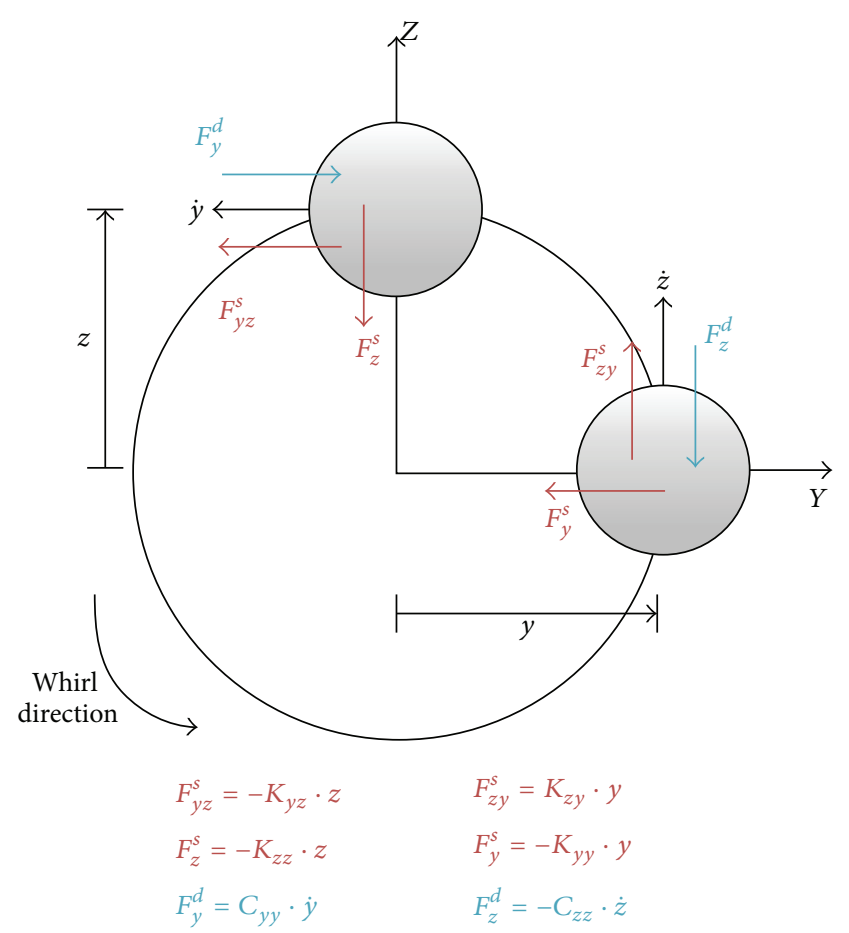

FIGURE 12: Representation of the forces acting on the shaft inside the journal bearing.

diagram) validation. In both cases, the instability threshold and the instability cause (oil-whirl or oil-whip) could be successfully identified through the models, presenting good agreement with experimental results even though no model adjustment techniques were used. Hence, the linear coefficients approach could be used in the design stage as a first indicative of the machine instability limit. Finally, a discussion about the instability mechanism and how it is affected by the bearing load and the bearing load capacity was presented.

\section{Appendix}

The matrixes used to build the finite element model are given by

$$
\begin{aligned}
\mathbf{M}_{\mathrm{T}}= & \frac{\rho A L_{e}}{420} \\
& {\left[\begin{array}{cccccccc}
156 & & & & & & \\
0 & 156 & & & & & \\
0 & -22 L_{e} & 4 L_{e}^{2} & & & & \\
22 L_{e} & 0 & 0 & 4 L_{e}^{2} & & & \\
54 & 0 & 0 & 13 L_{e} & 156 & & \\
0 & 54 & -13 L_{e} & 0 & 0 & 156 & \\
0 & 13 L_{e} & -3 L_{e}^{2} & 0 & 0 & 22 L_{e} & 4 L_{e}^{2} \\
-13 L_{e} & 0 & 0 & -3 L_{e}^{2} & -22 L_{e} & 0 & 0 & 4 L_{e}^{2}
\end{array}\right], }
\end{aligned}
$$

$$
\begin{aligned}
& \mathbf{M}_{\mathbf{R}}=\frac{\rho d_{e}^{2}}{480 L_{e}} \\
& {\left[\begin{array}{cccccccc}
36 & & & & & & & \\
0 & 36 & & & & & \text { sym. } \\
0 & -3 L_{e} & 4 L_{e}^{2} & & & & & \\
3 L_{e} & 0 & 0 & 4 L_{e}^{2} & & & & \\
-36 & 0 & 0 & -3 L_{e} & 36 & & & \\
0 & -36 & 3 L_{e} & 0 & 0 & 36 & & \\
0 & -3 L_{e} & -L_{e}^{2} & 0 & 0 & 3 L_{e} & 4 L_{e}^{2} & \\
3 L_{e} & 0 & 0 & -L_{e}^{2} & -3 L_{e} & 0 & 0 & 4 L_{e}^{2}
\end{array}\right]} \\
& \mathbf{G}=\frac{\rho A d_{e}^{2}}{240 L_{e}} \\
& {\left[\begin{array}{cccccccc}
0 & & & & & & & \\
36 & 0 & & & & \text { skew } & \text { sym. } \\
-3 L_{e} & 0 & 0 & & & & & \\
0 & -3 L_{e} & 4 L_{e}^{2} & 0 & & & & \\
0 & 36 & -3 L_{e} & 0 & 0 & & & \\
-36 & 0 & 0 & -3 L_{e} & 36 & 0 & & \\
-3 L_{e} & 0 & 0 & L_{e}^{2} & 3 L_{e} & 0 & 0 & \\
0 & -3 L_{e} & -L_{e}^{2} & 0 & 0 & 3 L_{e} & 4 L_{e}^{2} & 0
\end{array}\right]} \\
& \mathbf{K}=\frac{E I_{y y}}{L_{e}{ }^{3}} \\
& \cdot\left[\begin{array}{cccccccc}
12 & & & & & & & \\
0 & 12 & & & & & \text { sym. } \\
0 & -6 L_{e} & 4 L_{e}^{2} & & & & & \\
6 L_{e} & 0 & 0 & 4 L_{e}^{2} & & & & \\
-12 & 0 & 0 & -6 L_{e} & 12 & & & \\
0 & -12 & 6 L_{e} & 0 & 0 & 12 & & \\
0 & -6 L_{e} & 2 L_{e}^{2} & 0 & 0 & 6 L_{e} & 4 L_{e}^{2} & \\
6 L_{e} & 0 & 0 & 2 L_{e}^{2} & -6 L_{e} & 0 & 0 & 4 L_{e}^{2}
\end{array}\right],
\end{aligned}
$$

where the area moment of inertia $I_{y y}$ is given by

$$
I_{y y}=I_{z z}=\frac{\pi}{64} d_{e}^{4} .
$$

\section{Notation}

\section{Roman Letters}

$d_{e}$ : Shaft element diameter

$h$ : Fluid film thickness

$L_{e}:$ Shaft element length

p: Pressure 


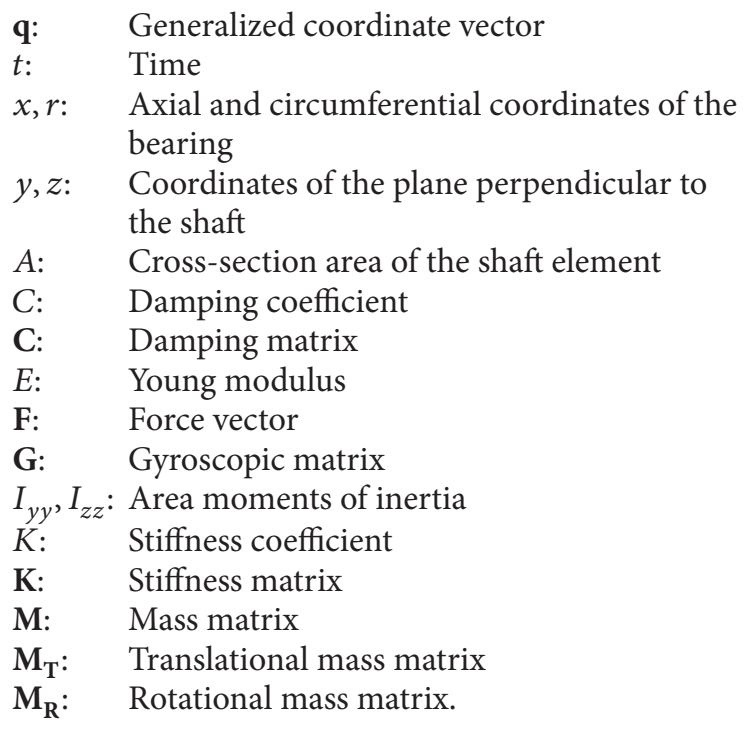

\section{Geek Letters}
$\Delta$ : Infinitesimal variation
$\rho$ : Shaft material density
$\mu$ : Fluid viscosity
$\Omega$ : Rotational speed.

\section{Superscripts}

$\because$ Differentiation with respect to time

$d$ : Force due to a damping coefficient

$s$ : Force due to a stiffness coefficient.

\section{Subscript \\ 0: Equilibrium position.}

\section{Conflict of Interests}

The authors declare that there is no conflict of interests regarding the publication of this paper.

\section{Acknowledgments}

The authors would like to thank the funding support by $\mathrm{CNPq}$ (Conselho Nacional de Desenvolvimento Científico e Tecnológico) (Grant no. 131658/2010-7); CAPES (Coordenação de Aperfeiçoamento de Pessoal de Nível Superior) (PROBRAL 341/10); and FAPESP (Fundação de Amparo à Pesquisa do Estado de São Paulo) (Grant no. 2007/54647-4).

\section{References}

[1] N. P. Petrov, "Friction in machines and the effect of lubricant," Inzhenernyj Zhurnal, Sankt-Peterburg, vol. 1, pp. 71-140, 1883.

[2] N. P. Petrov, "Friction in machines and the effect of lubricant," Inzhenernyj Zhurnal, Sankt-Peterburg, vol. 2, pp. 228-279, 1883.

[3] N. P. Petrov, "Friction in machines and the effect of lubricant," Inzhenernyj Zhurnal, Sankt-Peterburg, vol. 3, pp. 377-436, 1883.
[4] N. P. Petrov, "Friction in machines and the effect of lubricant," Inzhenernyj Zhurnal, Sankt-Peterburg, vol. 4, pp. 535-564, 1883.

[5] B. Tower, "First report on friction experiments (friction of lubricated bearings)," pp. 632-659, 1883, (Adjourned Discussion, pp. 29-35, 1884).

[6] B. Tower, "Second report on friction experiments (experiments on the oil pressure bearing)," Proceedings of the Institution of Mechanical Engineers, pp. 58-70, 1885.

[7] O. Reynolds, "On the theory of lubrication and its application to Mr. Beauchamp tower's experiments, including an experimental determination of the viscosity of olive oil," Philosophical Transactions of the Royal Society A, vol. 177, no. 1, pp. 157-234, 1886.

[8] G. Oliver, "An Introduction to Oil Whirl and Oil Whip," Turbo Components and Engineering Newsletter: Bearing Journal, vol. 3, no. 2, pp. 1-2, 2001.

[9] B. L. Newkirk, "Shaft Whipping," General Electric Review, vol. 27, article 169, 1924.

[10] B. L. Newkirk and H. D. Taylor, "Shaft whipping due to oil action in journal bearings," General Electric Review, vol. 28, pp. 559568, 1925.

[11] A. Muszynska, "Whirl and whip_rotor/bearing stability problems," Journal of Sound and Vibration, vol. 110, no. 3, pp. 443462, 1986.

[12] A. Muszynska, "Stability of whirl and whip in rotor/bearing systems," Journal of Sound and Vibration, vol. 127, no. 1, pp. 4964, 1988.

[13] A. Stodola, "Kritische Wellenstörung infolge der Nachgiebigkeit des Oelpolsters im Lager," Schweizerische Bauzeitung, vol. 85-86, pp. 265-266, 1925 (German).

[14] C. Hummel, Kritische drehzahlen als folge der nachgiebigkeit des schmiermittels im lager [Thesis], Eidgenössischen Technischen Hochschule, Zurich, Switzerland, 1926 (German).

[15] J. W. Lund, "Spring and damping coefficients for the tilting pad journal bearing," ASLE Transactions, vol. 7, no. 4, pp. 342-352, 1964.

[16] T. H. Machado and K. L. Cavalca, "Evaluation of dynamic coefficients of fluid journal bearings with different geometries," in Proceedings of the 20th Brazilian congress of mechanical engineering (COBEM '09), ABCM, Gramado, Brazil, November 2009.

[17] T. H. Machado, Evaluation of hydrodynamic bearings with geometric discontinuities [Dissertation], University of Campinas, Campinas, Brazil, 2011 (Portuguese).

[18] G. Capone, "Orbital motions of rigid symmetric rotor supported on journal bearings," La Meccanica Italiana, vol. 199, pp. 37-46, 1986 (Italian).

[19] G. Capone, "Analytical description of fluid-dynamic force field in cylindrical journal bearing," L'Energia Elettrica, vol. 3, pp. 105-110, 1991 (Italian).

[20] J. M. Vance, Rotordynamics of Turbomachinery, John Wiley \& Sons, New York, NY, USA, 1st edition, 1988.

[21] E. Krämer, Dynamics of Rotors and Foundations, Springer, New York, NY, USA, 1st edition, 1993.

[22] D. Childs, Turbomachinery Rotordynamics: Phenomena, Modeling, and Analysis, Wiley-Interscience, New York, NY, USA, 1st edition, 1993.

[23] E. N. Lima, Non-linear model for hydrodynamic sustaining forces on vertical rotors journal bearings [Dissertation], University of Campinas, Campinas, Brazil, 1996 (Portuguese). 
[24] H. F. de Castro, K. L. Cavalca, and R. Nordmann, "Whirl and whip instabilities in rotor-bearing system considering a nonlinear force model," Journal of Sound and Vibration, vol. 317, no. 1-2, pp. 273-293, 2008.

[25] H. D. Nelson and J. M. McVaugh, "The dynamics of rotorbearing systems using finite elements," Journal of Engineering for Industry, vol. 98, no. 2, pp. 593-600, 1976.

[26] A. A. G. Siqueira, R. Nicoletti, N. Norrick et al., "Linear parameter varying control design for rotating systems supported by journal bearings," Journal of Sound and Vibration, vol. 331, no. 10, pp. 2220-2232, 2012.

[27] B. Riemann, E. A. Perini, K. L. Cavalca, H. F. Castro, and S. Rinderknecht, "Oil whip instability control using $\mu$-synthesis technique on a magnetic actuator," Journal of Sound and Vibration, vol. 332, no. 4, pp. 654-673, 2013.

[28] J. Tuma, J. Simek, J. Skuta, and J. Los, "Active vibrations control of journal bearings with the use of piezoactuators," Mechanical Systems and Signal Processing, vol. 36, no. 2, pp. 618-629, 2013.

[29] R. U. Mendes, L. O. S. Ferreira, and K. L. Cavalca, "Analysis of a complete model of rotating machinery excited by magnetic actuator system," Proceedings of the Institution of Mechanical Engineers C, vol. 227, no. 1, pp. 48-64, 2013.

[30] P. M. Santana, K. L. Cavalca, E. P. Okabe, and T. H. Machado, "Complex response of a rotor-bearing-foundation system," in Proceedings of the 8th IFToMM International Conference on Rotordynamics, vol. 1, pp. 1-8, KAIST University, Seoul, Republic of Korea, September 2010.

[31] T. H. Machado and K. L. Cavalca, "Dynamic analysis of cylindrical hydrodynamic bearings with geometric discontinuities," in Proceedings of the 10th International Conference on Vibration Problems (ICOVP '11), J. Náprstek, J. Horáček, M. Okrouhlík, B. Marvalová, F. Verhulst, and J. T. Sawicki, Eds., vol. 139 of Proceedings in Physics, pp. 537-542, Springer, Prague, Czech Republic, September 2011.

[32] J. W. Lund, "Review of the concept of dynamic coefficients for fluid film journal bearings," Journal of Tribology, vol. 109, no. 1, pp. 37-41, 1987. 

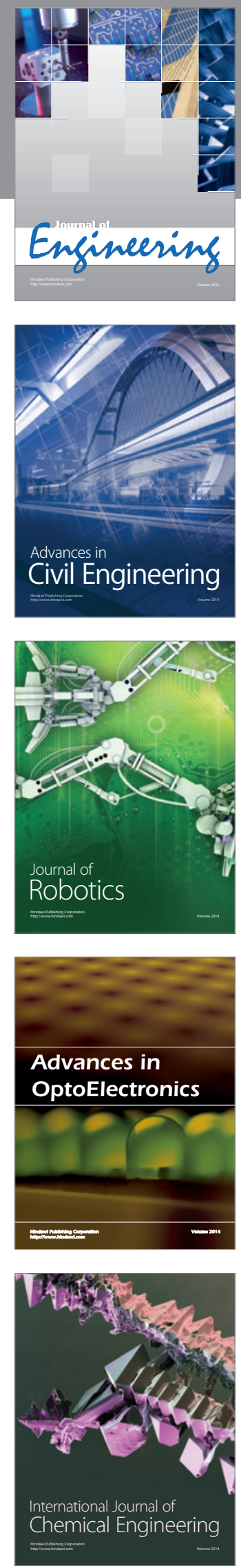

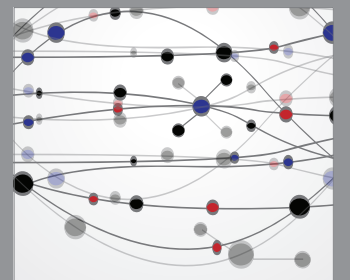

The Scientific World Journal
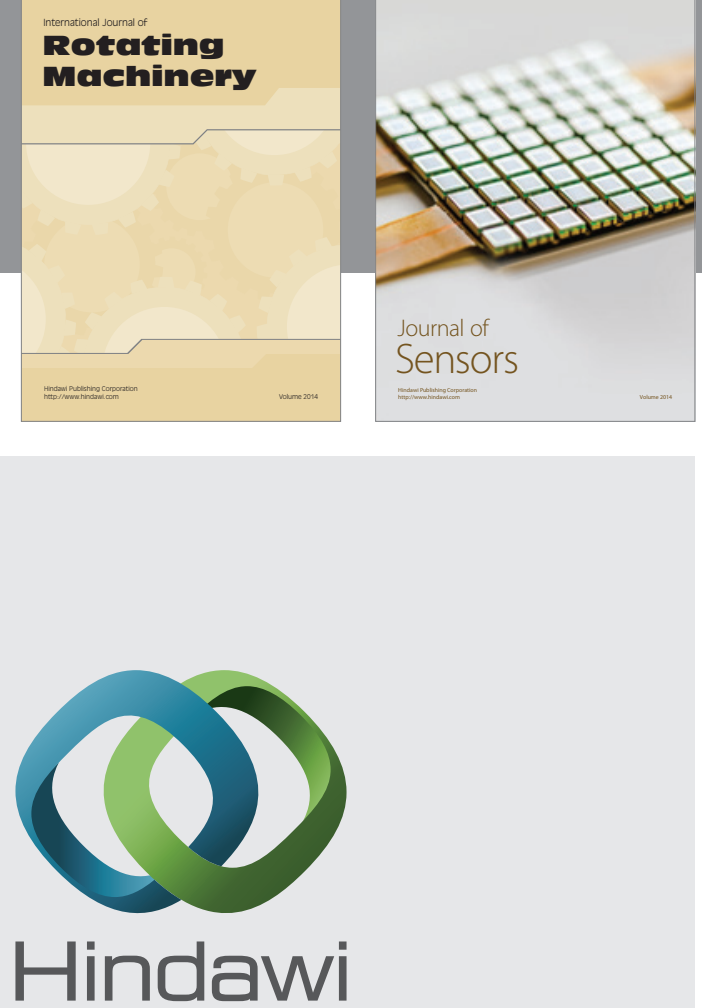

Submit your manuscripts at http://www.hindawi.com
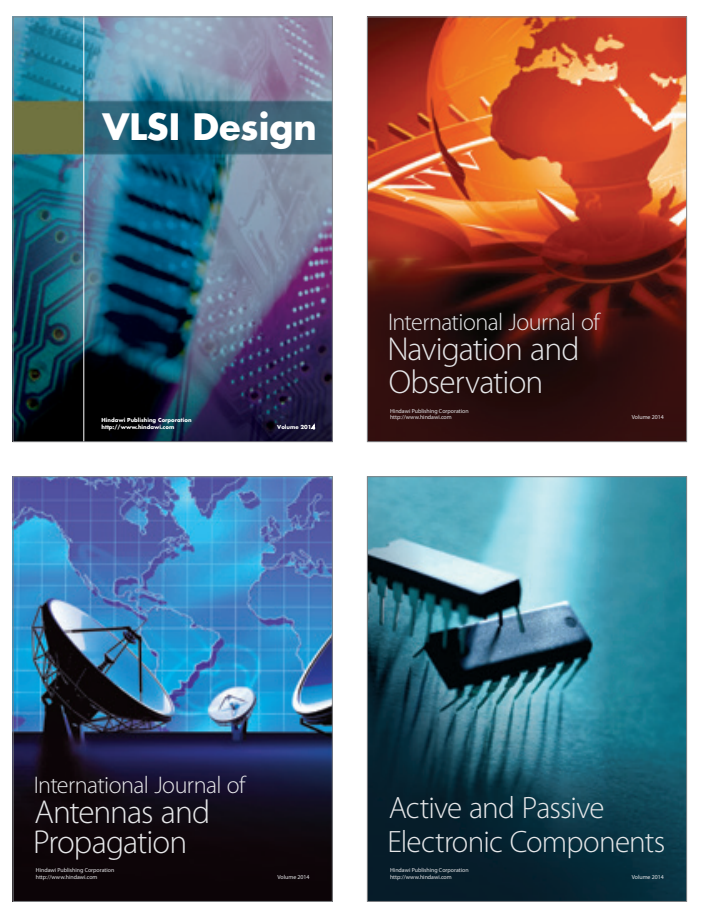
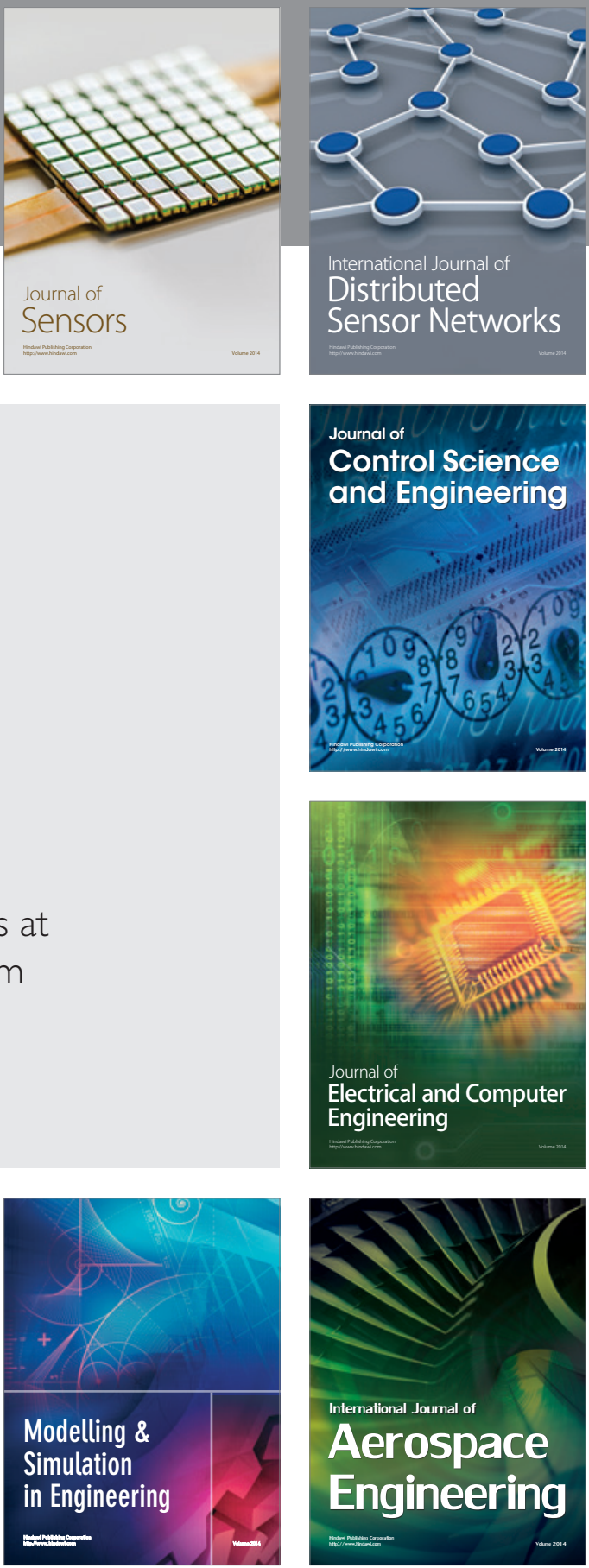

Journal of

Control Science

and Engineering
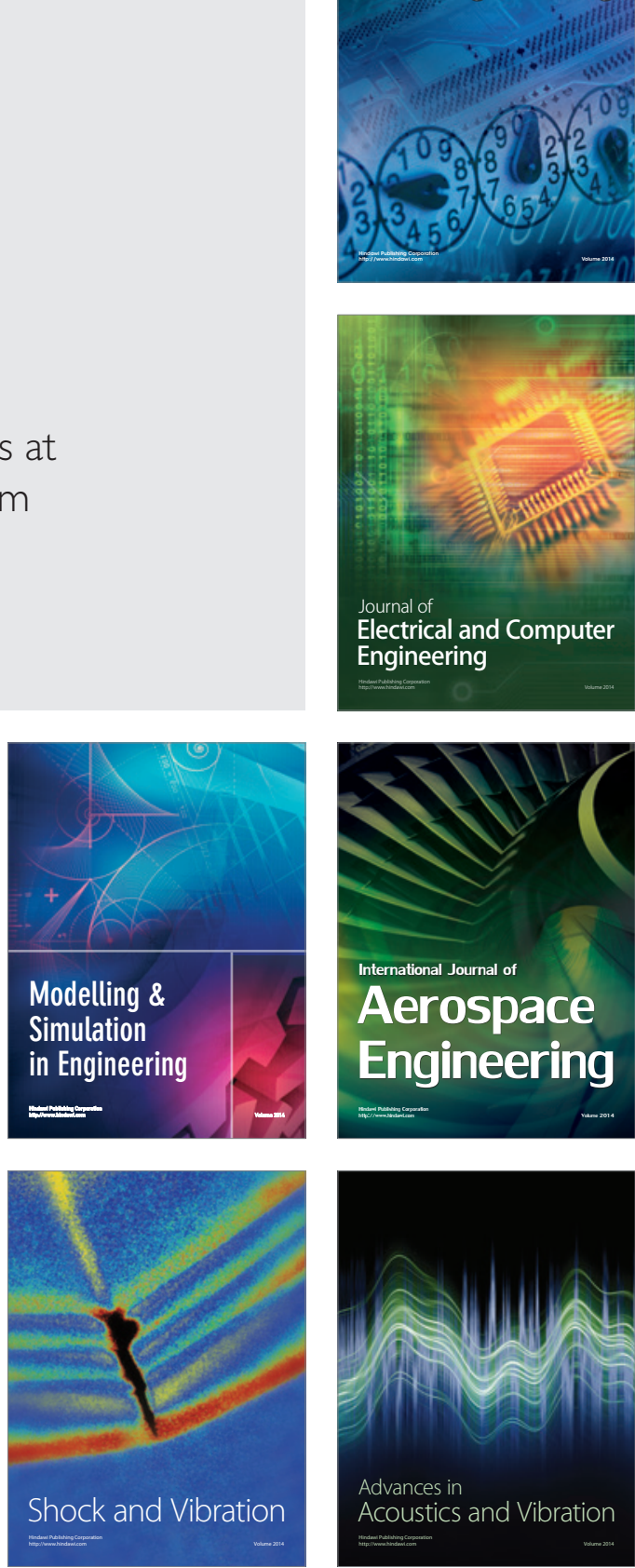